NISTIR 89-3911

\title{
IGNITION CHARACTERISTICS OF THE NICKEL-BASED ALLOY UNS N07718 IN PRESSURIZED OXYGEN
}

James W. Bransford

Phillip A. Billiard

James A. Hurley

Kathleen M. McDermott

Isaura Vazquez

National Institute of Standards and Technology

(formerly National Bureau of Standards)

U.S. Department of Commerce

Boulder, Colorado 80303-3328

April 1989 

NISTIR 89-3911

\section{IGNITION CHARACTERISTICS OF THE NICKEL-BASED ALLOY UNS N07718 IN PRESSURIZED OXYGEN}

James W. Bransford Phillip A. Billiard James A. Hurley Kathleen M. McDermott Isaura Vazquez

Chemical Engineering Science Division Center for Chemical Engineering National Engineering Laboratory National Institute of Standards and Technology Boulder, Colorado 80303-3328

April 1989

Sponsored by

NASA

George C. Marshall Space Flight Center, AL 35812

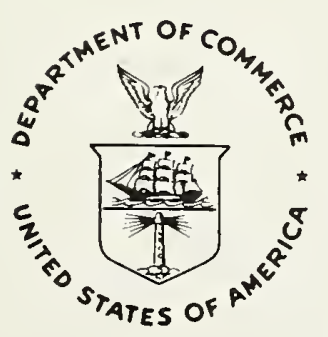



List of Figures............................ v

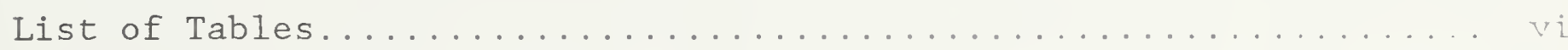

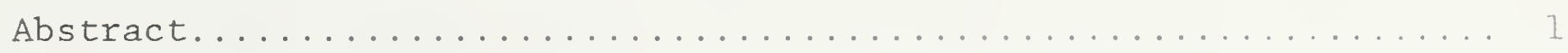

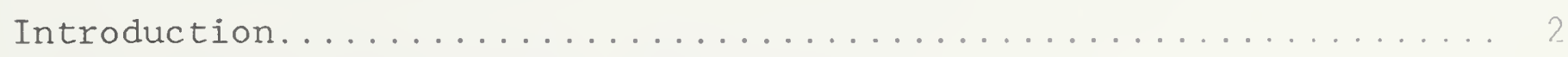

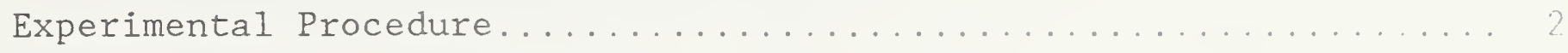

The Metal Ignition Process.........................

$\operatorname{Results\ldots \ldots \ldots \ldots \ldots \ldots \ldots \ldots \ldots \ldots \ldots \ldots \ldots \ldots \ldots }$

1. Linear Temperature Scan Tests...................... 17

2. Differential Thermal Analysis Studies............... 27

3. Incremental Temperature Scan Tests... . . . . . . . . . . . 29

4. Data Accuracy..............................

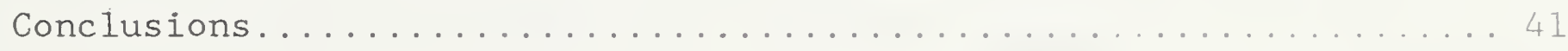

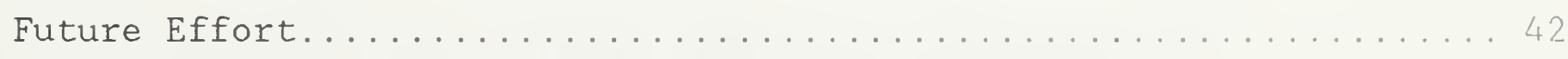

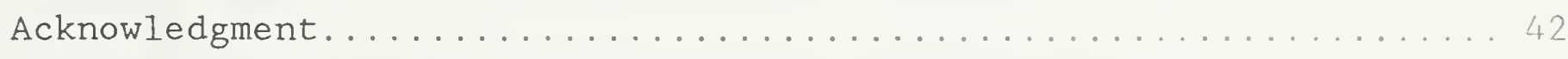

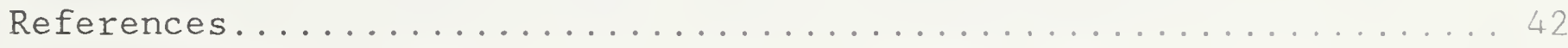



1. Test specimen configuration.....................

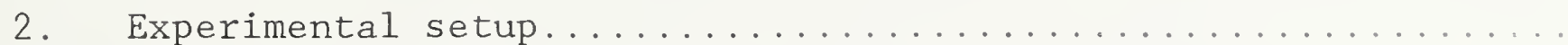

3. Test chamber configuration

4. General variation of heat balance parameters

as a function of surface temperature.................... II

5. Development of ignition during an ITS test.............. 15

6. Abrupt ignition and combustion event during an LTS test....... 18

7. Typical surface and interior temperature waveforms for an LTS

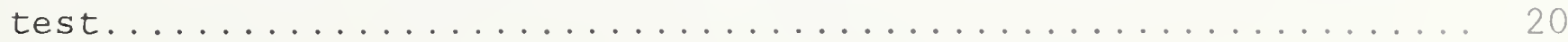

8. Surface temperature waveform features from an LTS test....... 22

9. Ignition temperatures vs. oxygen pressure from the LTS tests... 25

10. Combustion temperatures vs. oxygen pressure from the LTS tests.. 26

11. DTA thermograph of N07718 alloy heated in oxygen.......... 28

12. Typical surface and interior temperature waveforms for

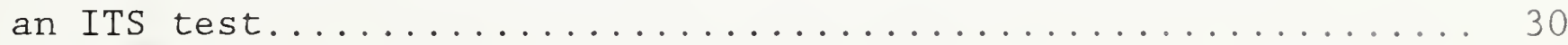

13. Development of ignition in $5.488 \mathrm{MPa}$ oxygen during an ITS test.. 31

14. Development of ignition in $14.410 \mathrm{MPa}$ oxygen during an ITS test. 32

15. Spontaneous ignition temperatures vs. oxygen pressure

from the ITS tests......................... 36

16. Enhanced oxidation temperatures vs. oxygen pressure

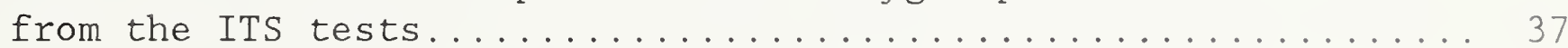

17. Ignition temperatures vs. oxygen pressure from the ITS test.... 38 
1. Composition, in percent, of materials selected for the determination of ignition and combustion characteristics.....

2. LTS ignition and combustion temperatures.............. 24

3. ITS ignition parameter temperatures............... 35

4. Linear least-squares curve fit coefficients for the ITS

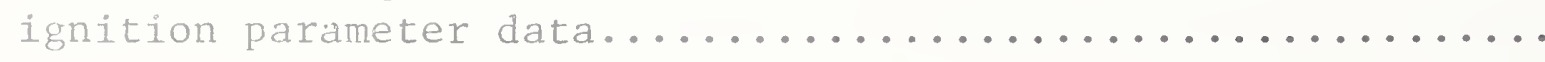


Ignition Characteristics of the Nicke1-Based Alloy UNS N07718 In Pressurized Oxygen

James W. Bransford, Phillip A. Billiard,

James A. Hurley, Kathleen M. McDermott,

and Isaura Vazquez

The development of ignition and combustion in pressurized oxys

atmospheres was studied for the nickel-based alloy UNS N07718. Ignition of the alloy was achieved by heating the cop surface of a cylindrical specimen with a continuous-wave $\mathrm{CO}_{2}$ laser. Two heating procedures were used. In the first, laser power was adjusted to maintain an approximately linear increase in surface temperature. In the second, laser power was periodically increased until autoheating (self-heating) was established. It was found that the alloy would autoheat to destruction from temperatures below the solidus temperature. In addition, endothermic events occurred as the alloy was heated, many at reproducible temperatures. Many endothermic events occurred prior to abrupt increases in surface temperature and appeared to accelerate the rate of increase in specimen temperature. It appeared that the source of some endotherms may increase the oxidation rate of the alloy. Ignition parameters are defined and the temperatures at which these parameters occur are given for the oxygen pressure range of 1.72 to $13.8 \mathrm{MPa}$ (250 to 2000 psia).

Key words: alloys; combustion; ignition; ignition temperature; metals; nickel alloys. 


\section{Introduction}

A number of serious accidents and catastrophic fires have occurred that involved the ignition and subsequent combustion of metals in oxygen systems. As the pressure in oxygen systems has increased, the potential for disastrous ignition and combustion has also increased. In order to reduce the potential for ignition and combustion failure in oxygen systems, a knowledge of the ignition and combustion characteristics of metals is needed. In recognizing this need, the George C. Marshall Space Flight Center (MSFC) initiated a program at the National Institute of Standards and Technology (NIST) to study the ignition and combustion characteristics of selected alloys in pressurized oxygen. A list of alloys that have been studied is given in table 1 .

This report, the second in a series, gives the results for the nickelbased alloy UNS N07718. The studies involved heating the top surface of specimens of the material by a continuous-wave (cw) $\mathrm{CO}_{2}$ laser in pressurized oxygen. The surface and interior temperatures were recorded as the specimens were heated. High-speed cinematography of the ignition and combustion events was also obtained. From this information the spontaneous ignition (critical) temperature, enhanced oxidation temperature (our terminology), ignition temperature, combustion temperature, ignition and combustion morphology, and other information were obtained for the oxygen pressure range of 1.72 to 13.80 MPa (250 to 2000 psia).

\section{Experimental Procedure}

Cylindrical test specimens, figure 1, were machined from commercially available UNS N07718 alloy rod that had a hardness of Rockwell C 24-27. The rod had a chemical composition of $0.50 \% \mathrm{~A} 1,0.0038 \mathrm{~B}, 0.0368 \mathrm{C}, 0.348$ Co, $17.628 \mathrm{Cr}, 0.098 \mathrm{Cu}, 20.038 \mathrm{Fe}, 0.148 \mathrm{Mn}, 2.908 \mathrm{Mo}, 51.528 \mathrm{Ni}, 0.0078 \mathrm{P}$, 


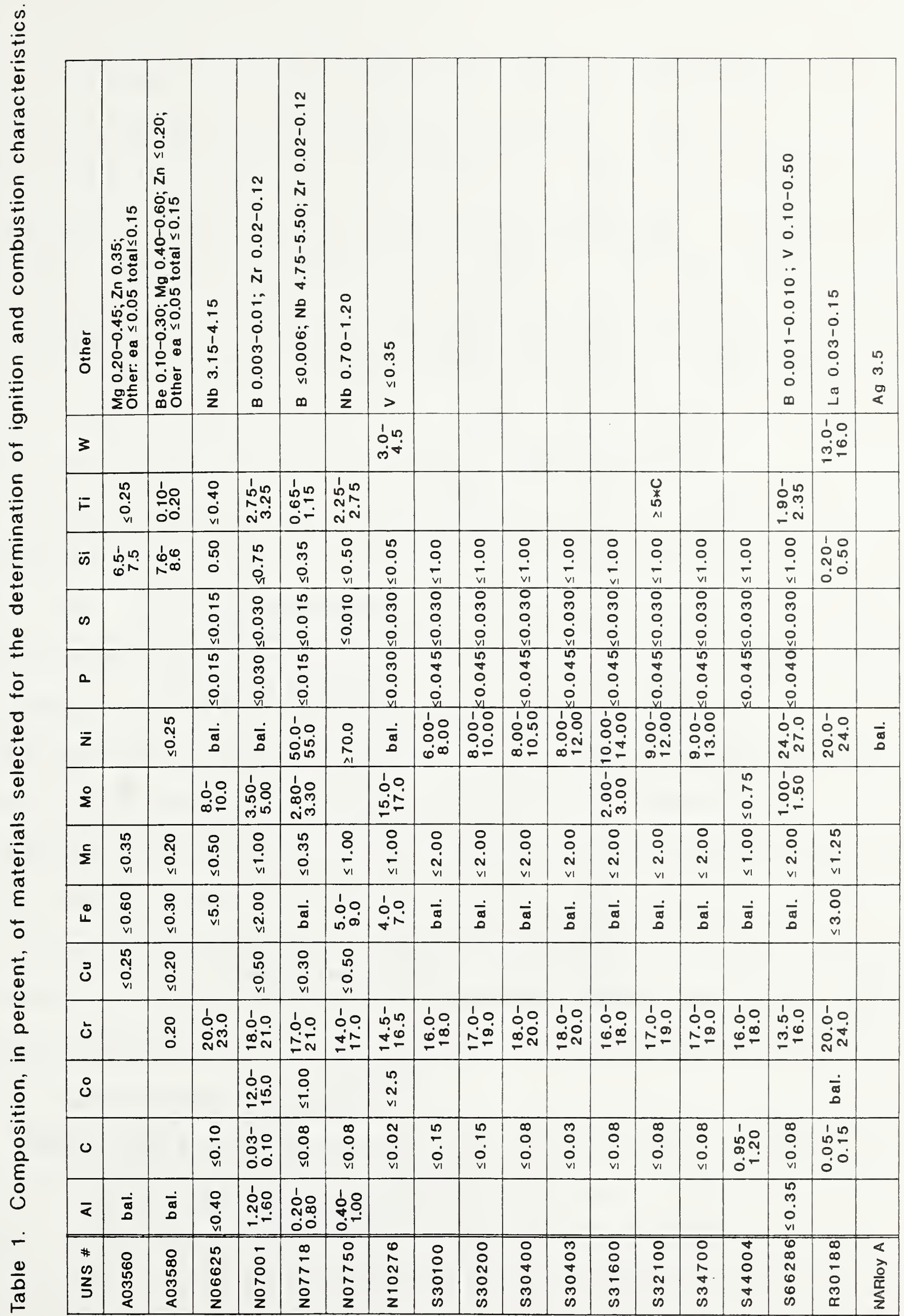



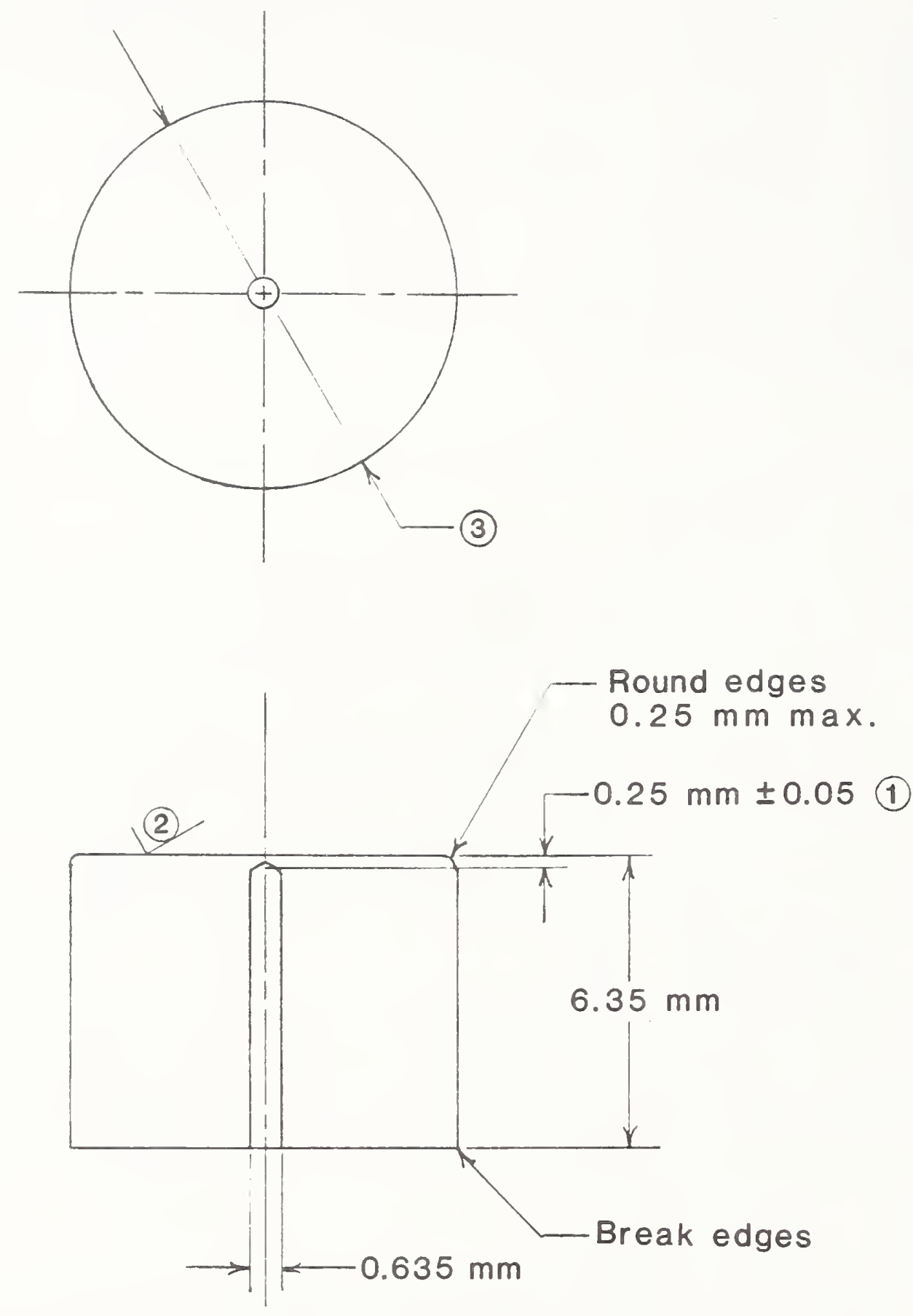

NOTES:

1. Apex to top surface center.

2. Surface finish as specified.

3. $6.35 \mathrm{~mm}$ or $8.00 \mathrm{~mm}$ dia. as required.

Figure 1. Test specimen configuration. 
$0.001 \% \mathrm{~S}, 0.068 \mathrm{Si}, 0.92 \% \mathrm{Ti}, 5.11 \% \mathrm{Cb}+\mathrm{Ta}$. Specimen dimensions were $6.3 \mathrm{~mm}$ (0.25 in) in diameter by $6.3 \mathrm{~mm}(0.25 \mathrm{in})$ in height for the linear temperature increase tests and $8.0 \mathrm{~mm}(0.31 \mathrm{in})$ in diameter by $6.3 \mathrm{~mm}(0.25$ in) in height for the incremental temperature increase tests. A thermocouple hole was drilled axially to within $0.25 \mathrm{~mm}(0.010 \mathrm{in}) \pm 0.05 \mathrm{~mm}(0.002 \mathrm{in})$ of the top surface. The top surfaces of the specimen were maintained in the as machined finish to improve the absorptivity of the surface to the laser beam at the beginning of an experiment and to give a diffuse laser beam reflection which would minimize potential heat damage to the chamber liner.

The experiments were carried out in commercially pure oxygen. Chamber pressure was varied from 1.72 to $13.8 \mathrm{MPa}$ (250 to $2000 \mathrm{psia}$ ) in $1.72 \mathrm{MPa}$ (250 psia) steps. Oxygen pressures lower than $1.72 \mathrm{MPa}$ could not be used because gaseous oxides, produced during the high temperature combustion phase of the experiments, created splatter which destroyed the laser beam window after several experiments. The chamber pressure was allowed to increase, due to heating of the oxygen, during the experiments and was recorded at the beginning of specimen combustion. This pressure increase rarely exceeded the initial chamber pressure by 10 percent.

To assemble an experiment, a specimen was mounted in a machined graphite block and was insulated from the block by packed aluminum oxide powder. This assembly was placed upon a ceramic foam pad which was then placed on a pedestal as shown in figure 2 .

The top surface of the specimen was heated by a $\mathrm{cw} \mathrm{CO}_{2}$ laser beam. The laser had been detuned from the pure $\mathrm{TEM}_{\mathrm{O}}$ mode so as to contain higher order modes. This procedure distributes the laser power more uniformly across the laser beam and heats the specimen more uniformly. The laser beam was focused 


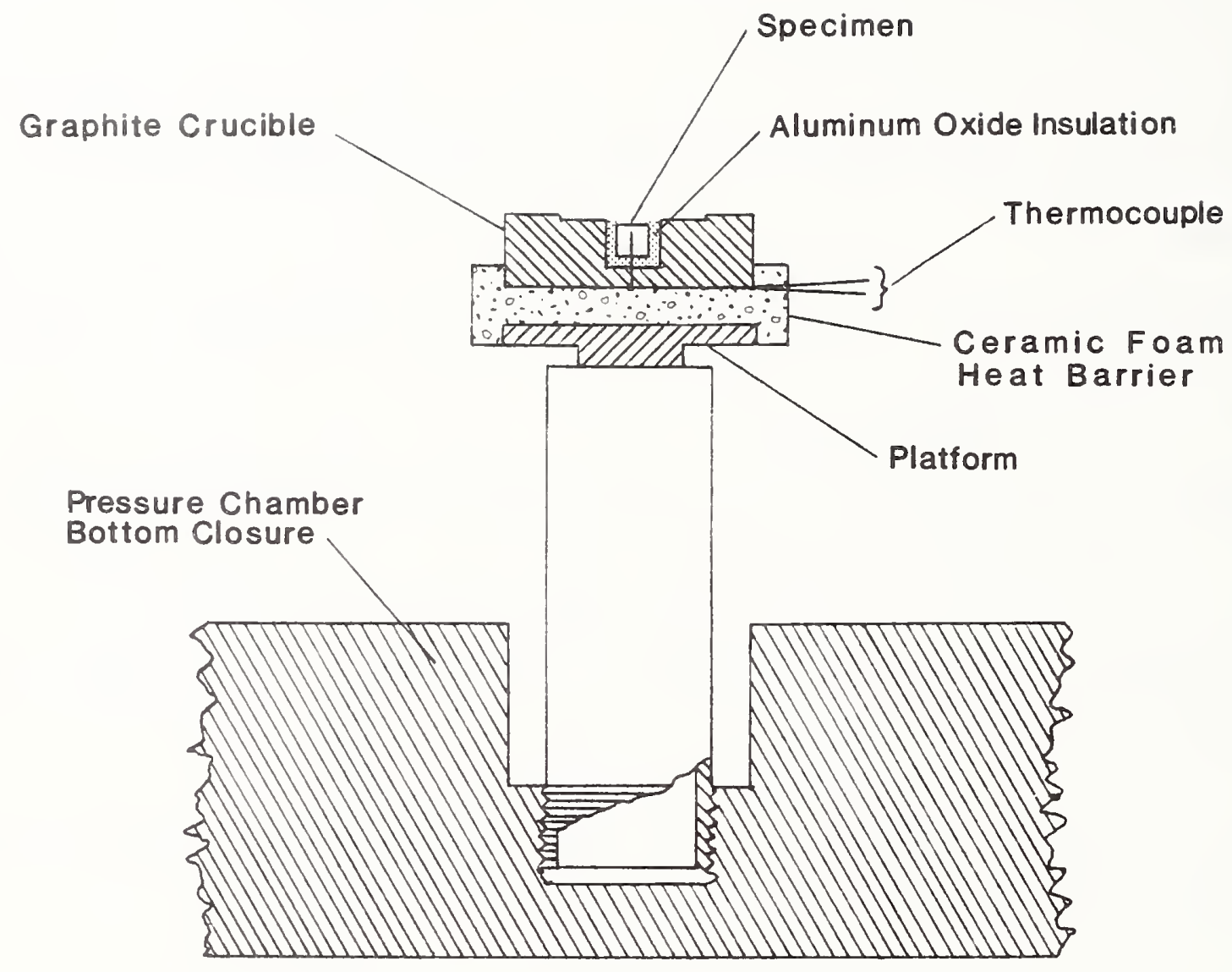

Figure 2. Experimental setup. 
to cover approximately 80 percent of the top surface of the specimen. This allowed the beam to remain predominantly on the specimen surface despite random refraction of the beam by gas convection currents rising from the heated surface.

Two heating procedures were used in this study. The first procedure established and maintained an approximately linear increase in specimen surface temperature and was called the Linear Temperature Scan (LTS) heating procedure. Surface heating rates of $100 \mathrm{~K} / \mathrm{min}$ were most often used; however, rates of up to $250 \mathrm{~K} / \mathrm{min}$ were used occasionally. The LTS heating procedure was used primarily to determine whether rapidly developing exothermic events including ignition, were present, but the tendency of a material to autoheat (self-heat), which is usually a much slower exothermic process, was also detectable.

The second heating procedure incrementally increased the laser beam power. The surface was allowed to reach a short-term equilibrium before another power increment was applied. At some power level during the procedure, the surface temperature would not reach equilibrium and the material would autoheat to destruction. This procedure was called the Incremental Temperature Scan (ITS) heating procedure.

The principal parameters in this study were the surface temperature and interior temperature of the specimen. The surface temperature was measured using two-color ratio pyrometry. Two pyrometers were ultimately used. One pyrometer covered the temperature range of 973 to $1773 \mathrm{~K}$ (1292 to $2732^{\circ} \mathrm{F}$ ) and had an output range which gave a temperature sensitivity of $8 \mathrm{~K} / \mathrm{mV}$ (14 ${ }^{\circ} \mathrm{F} / \mathrm{mV}$ ). The second pyrometer covered the temperature range of 1173 to $2673 \mathrm{~K}$ (1652 to $4352^{\circ} \mathrm{F}$ ) and had an output range which gave a temperature sensitivity 
of $15 \mathrm{~K} / \mathrm{mV}\left(27^{\circ} \mathrm{F} / \mathrm{mV}\right)$. These signals were recorded by a digital oscilloscope which used 15 bit analog to digital (A/D) converters. These converters have a maximum signal voltage resolution of $6.25 \mu \mathrm{V}$. Thus, maximum temperature resolution was $0.05 \mathrm{~K}\left(0.09^{\circ} \mathrm{F}\right)$ for the 973 to $1773 \mathrm{~K}$ range pyrometer and $0.09 \mathrm{~K}\left(0.16^{\circ} \mathrm{F}\right)$ for the 1173 to $2673 \mathrm{~K}$ range pyrometer.

The pyrometers viewed the specimen through the pressure chamber windows, figure 3 , at $45^{\circ}$ from the vertical. The specimen surface observed within the pyrometers' circular measurement field of view was elliptical and covered top surface dimensions that varied from approximately 5 to $7 \mathrm{~mm}(0.2$ to $0.3 \mathrm{in})$. The pyrometers did not measure the maximum surface temperature but responded to the overall temperature of the viewed area. The temperature was not an average but was biased toward the highest temperature within the measurement area due to the non-linear dependence of radiated power on temperature.

The interior temperature was measured using a platinum versus platinum108 rhodium (Type S) thermocouple. The thermocouple was insulated except for the bead, which was in contact with the specimen at the top of the thermocouple well. The output of the thermocouple was referenced to a $273 \mathrm{~K}$ cold junction and then digitized directly at the maximum sensitivity of the digitizers, $6.25 \mu \mathrm{V}$. This gave a temperature sensitivity of approximately $0.6 \mathrm{~K}\left(1^{\circ} \mathrm{F}\right)$ over the temperature range of interest, 973 to $1773 \mathrm{~K}$.

Special tests in which the thermocouple was spot-welded to the top surface were also run. These tests were used to obtain estimates of the temperatures of the alloy/oxide interface.

\section{The Metal Ignition Process}

A detailed description of the ignition process of metals requires a significant number of parameters; however, a general understanding of the 


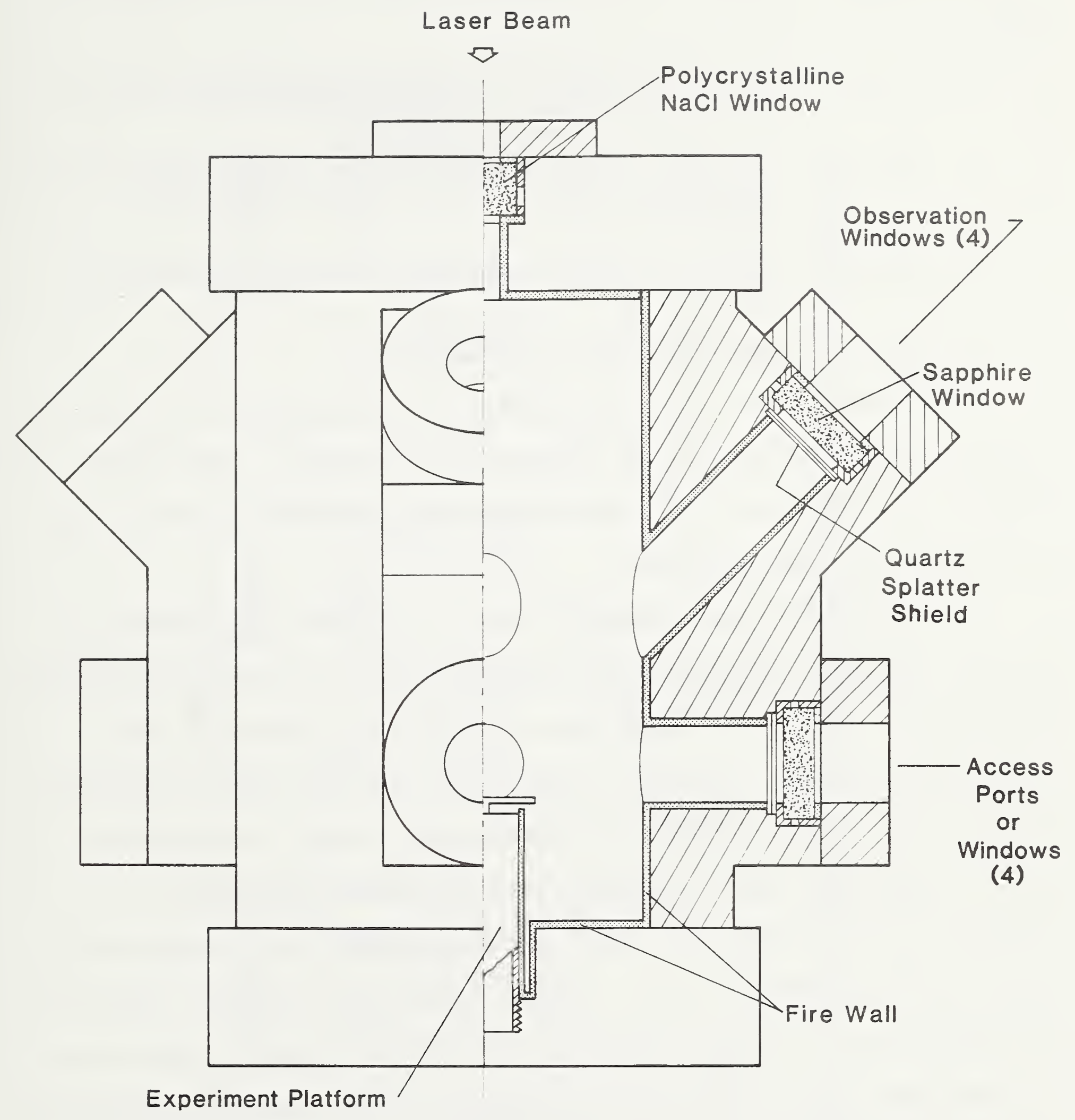

Figure 3. Test chamber configuration. 
process can be obtained by considering a generalized heat balance for an oxidizing surface, figure 4. The parameters that need to be incorporated are:

1. $\dot{Q}($ loss $)$ - the rate at which the oxidizing surface loses heat by conduction, convection and radiation;

2. $\dot{Q}(e x t)$ - the rate at which external sources transfer heat to the oxidizing surface by conduction, convection and radiation;

3. $\dot{Q}($ chem $)$ - the rate at which oxidation of the alloy generates heat;

4. $\dot{Q}(\mathrm{in})$ - the sum of $\dot{Q}$ (ext) and $\dot{Q}$ (chem).

To further simplify the process, $\dot{Q}($ ext) will be assumed a constant, but different value, for each of the illustrations in figure 4. Both $\dot{Q}($ loss) and $\dot{Q}$ (chem) are functions of the surface temperature and other parameters which are constant for this discussion.

An initial application of $\dot{Q}($ ext), which is less than that required to initiate ignition, will increase the magnitude of $\dot{Q}(i n)$ to some value greater than $\dot{Q}($ loss $)$. The surface temperature, $\mathrm{T}_{\mathbf{S}}$, will then increase to some equilibrium value $\mathrm{T}_{\mathrm{eq}}$, as shown in figure $4 \mathrm{a}$. Since the slope of the $\dot{\mathrm{Q}}$ (in) curve is less than the slope of the $\dot{Q}$ (loss) curve at $\mathrm{T}_{\mathrm{eq}}$, the oxidizing surface temperature cannot increase beyond $\mathrm{T}_{\mathrm{eq}}$ because the increase in heating rate will be less than the increase in cooling rate at temperatures greater than $\mathrm{T}_{\text {eq. }}$. Thus, a stable surface temperature is reached. However, the stability over time will depend upon whether the surface is undergoing time dependent or time independent oxidation. If time dependent oxidation is occurring, $\dot{Q}($ chem) will decrease with time and the oxidizing surface temperature will also decrease with time. If time independent oxidation is 

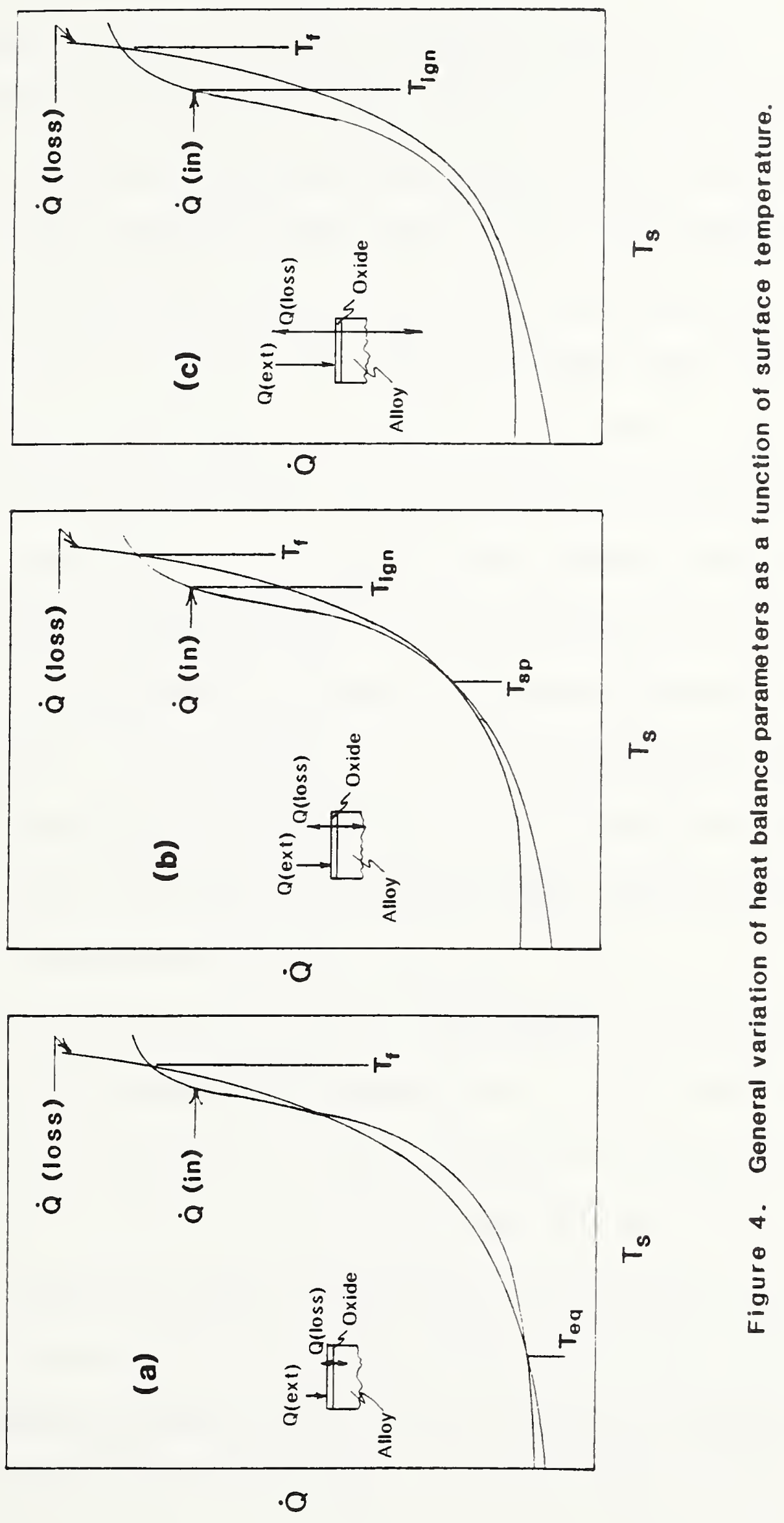
occurring, $\dot{Q}($ chem) will remain constant and the oxidizing surface temperature will remain constant if all other parameters remain constant.

As $\dot{Q}(e x t)$ is systematically increased, an equilibrium surface temperature will ultimately be reached at which the slope of the $\dot{Q}(i n)$ curve equals the slope of the $\dot{Q}($ loss) curve, figure $4 \mathrm{~b}$. This equilibrium temperature is defined as the spontaneous ignition (or critical) temperature, $\mathrm{T}_{\text {sp }}$ [1]. Since $\dot{Q}$ (chem) and $\dot{Q}$ (loss) both increase with increasing temperature, the slopes of the $\dot{Q}(\mathrm{in})$ and $\dot{Q}($ loss) curves may be approximately equal over a fairly wide temperature range. We have previously described this range as a quasi-stable temperature region [2]. The behavior of an alloy within this region is of considerable interest. Small shifts in other parameters which change any of the heat gain or heat loss parameters, can either cause the oxidizing surface to cool or to autoheat. Several parameters may be defined for the case when $\dot{Q}(i n)$ is sufficiently large for spontaneous ignition to occur:

1. Spontaneous ignition temperature, $\mathrm{T}_{\mathbf{s p}}{ }^{- \text {the }}$ temperature at which dQ (in) $/ \mathrm{dT}_{\mathrm{S}}=\mathrm{dQ}(10 \mathrm{ss}) / \mathrm{dT}_{\mathrm{S}}$;

2. Ignition temperature, $\mathrm{T}_{\text {ign }}{ }^{- \text {the }}$ temperature at which $[\dot{Q}($ in) $-\dot{Q}($ loss $)]$ is maximum;

3. Flame temperature, $\mathrm{T}_{\mathrm{f}}$--the maximum temperature that can be reached by the oxidizing surface.

These parameters are shown in figure $4 \mathrm{~b}$.

An equilibrium surface temperature greater than $\mathrm{T}_{\mathrm{sp}}$ may be established by decreasing $\dot{Q}\left(\right.$ ext) once the surface temperature has exceeded $T_{\mathbf{s p}}$. However, such an equilibrium surface temperature must be considered unstable because 
the tendency is for the alloy to autoheat since the slope of the $\dot{Q}$ (in) curve is greater than the slope of the $\dot{Q}$ (loss) curve.

It is useful to consider the effect of physical state on the parameters that have been introduced. In general, the oxidation rate of the solid alloy is less than that of the liquid alloy. Therefore, if $\mathrm{T}_{\mathrm{sp}}$ occurs while the alloy is solid, a phase-dependent ignition temperature may be definable. However, defining an ignition temperature for the liquid phase in our experiments was difficult because of the effects of fluid flow. When an oxidizing fluid flows, the rate of oxygen transport to unoxidized material may be significantly increased for a short time interval. This in turn increases the rate at which material is consumed and significantly increases the surface temperature for the flow interval. The net result of the fluid movement is to disrupt the smoothness of the $\dot{Q}$ (chem) curve, which makes it difficult to separate movement enhanced oxidation effects from quiescent oxidation effects. For this reason, liquid phase ignition temperatures were not determined for the ITS heating procedure (with the exception of the temperature at the beginning of combustion, $\mathrm{T}_{\mathrm{cmb}}$ ); only solid phase ignition parameters were determined.

If $\dot{Q}(e x t)$ is sufficiently large, the $\dot{Q}($ in) curve will not intersect the $\dot{Q}\left(\right.$ loss ) curve until $\mathrm{T}_{\mathrm{f}}$ is reached, figure $4 \mathrm{c}$. In this case $\mathrm{T}_{\mathrm{sp}}$ is not obtainable from the experiment; however, $\mathrm{T}_{\mathrm{ign}}$ and $\mathrm{T}_{\mathrm{f}}$ are. $\mathrm{T}_{\mathrm{ign}}$ does not differ in this case from the case shown in figure $4 \mathrm{~b}$. This is due to the definition of $\mathrm{T}_{\text {ign }}$ as being the temperature at the maximum deviation between the $\dot{Q}($ in) curve and the $\dot{Q}($ loss) curve. This means that our experiments, which use the ITS heating procedure, can be thermally overdriven without seriously affecting the value of $\mathrm{T}_{i g n}$. This statement assumes that the 
excess external heat input is slightly more than the minimum required to achieve ignition and not orders of magnitude more.

Since the exact shape and magnitude of the $\dot{Q}(\mathrm{in})$ and $\dot{Q}($ loss $)$ curves are not known, the determination of the ignition parameters must be based upon other measurable parameters. In our case the surface and interior temperatures were used.

As the surface temperature increases, the developing oxide layer emissivity changes, usually increases. In our tests in which a laser was used as the external heat source, this changing emissivity may result in increased heating at a constant laser power input without a corresponding increase in radiative cooling.

To determine the spontaneous ignition temperature, an apparent changing emissivity effect to specimen heating had to be separated from the oxidation contribution. This was accomplished by running a number of tests using preoxidized specimens. These tests, when compared to the standard test, showed that the contribution from the apparent changing emissivity to the specimen heating rate, under constant laser power, was linear or nearly linear [3]. Since the oxidation rate of metals and alloys is nonlinear with temperature, spontaneous ignition was assumed to have occurred when the temperature-time waveform became nonlinear under constant laser power input, figure 5. The temperature at the beginning of the nonlinear waveform segment was taken as the spontaneous ignition temperature.

We have defined an additional ignition parameter that is specific to our data. This parameter defines the beginning of a region on the ITS temperature-time waveform where an abrupt change in curvature occurs prior to ignition, figure 5. The region generally contains a number of abrupt 


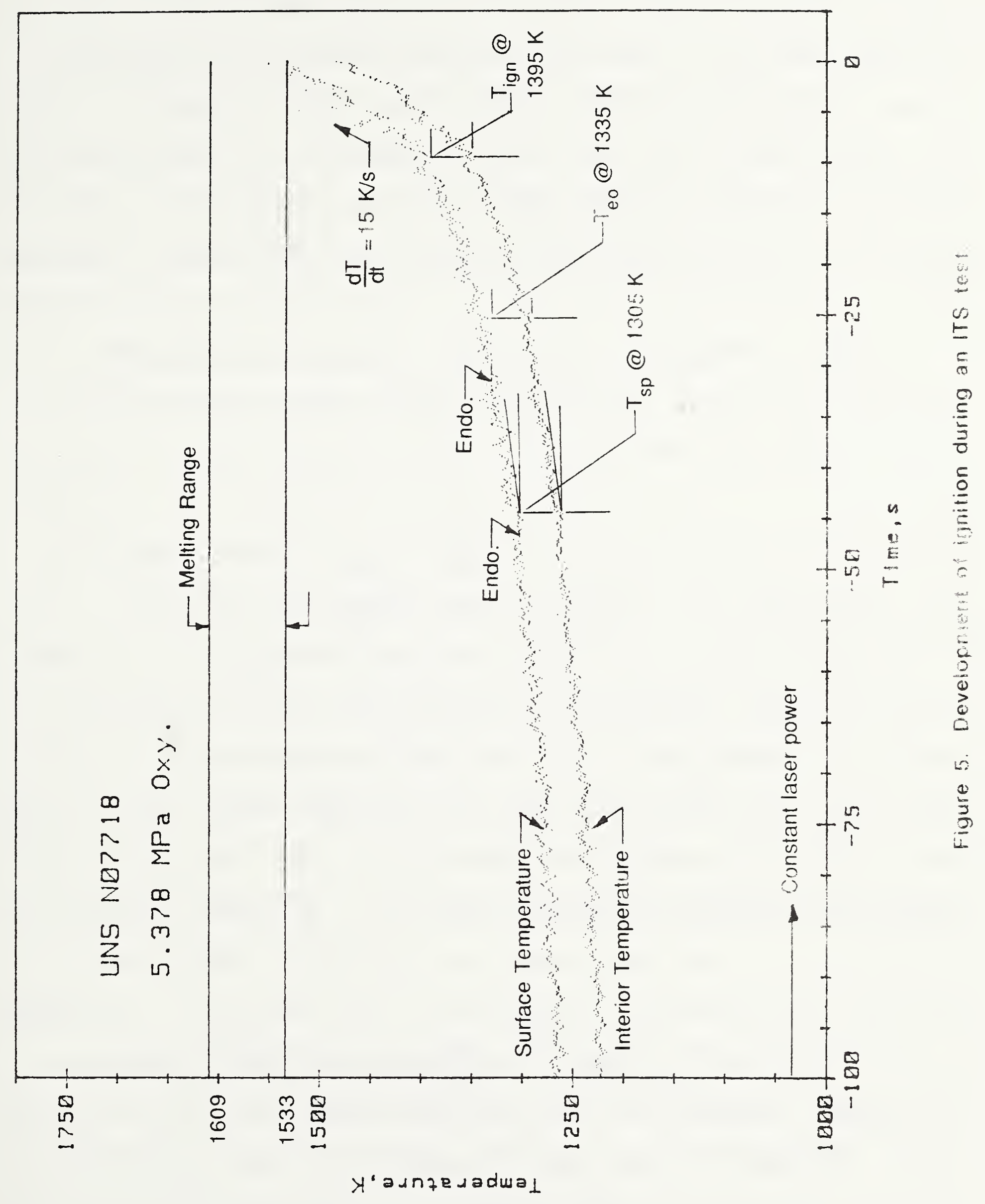


changes in temperature which appear in conjunction with endothermic features. Since many endothermic events are associated with the abrupt temperature changes, we postulated that the source of these events increased or enhanced the oxidation rate of the alloy. Thus, the temperature at the beginning of this region has been called the enhanced oxidation temperature, $\mathrm{T}_{\mathrm{eo}}$, and appears to be associated with the beginning of the rapid buildup of the oxide layer.

The ignition temperature was the most straightforward parameter to determine since the definition of this parameter implies the existence of a maximum heating rate of the specimen. This was assumed to have occurred when the maximum rate of change in surface temperature occurred, i.e., [Q(in) $\dot{Q}(10 s)]$ is maximum when $\mathrm{dT}_{\mathrm{S}} / \mathrm{dt}$ is maximum. $\mathrm{T}_{i g n}$ was the beginning of the region of maximum rate of change in surface temperature, figure 5.

A number of factors can influence the shape and magnitude of the $\dot{Q}(i n)$ and $\dot{Q}($ loss ) curves. The $\dot{Q}($ loss ) curve alone can be easily modified by improving or impeding heat transfer from the oxidizing interface. The $\dot{Q}(i n)$ curve may be modified by the existence of fluid oxide phases (which may exist above certain temperatures) at the oxidizing interface. These phases may increase the oxidation rate of many alloys [4,5]. The $\dot{Q}$ (chem) component of the $\dot{Q}(i n)$ curve is also modified when the oxidation rate changes from protective (time dependent) to nonprotective (time independent). When either $\dot{Q}($ in) or $\dot{Q}($ loss ) curve is changed, the values of the ignition parameters will also change. In general, the lower the heat transfer rate from the oxidizing surface, the lower the temperatures at which $\mathrm{T}_{\mathrm{sp}}, \mathrm{T}_{\mathrm{eo}}$, and $\mathrm{T}_{\mathbf{i g n}}$ will occur; conversely, the greater the heat transfer rate, the higher the temperature at which $\mathrm{T}_{\mathrm{sp}}, \mathrm{T}_{\text {eo }}$, and $\mathrm{T}_{\mathrm{ign}}$ will occur. 
Under certain experimental conditions and/or at elevated oxygen pressures, combustion may develop abruptly before the above-defined $\mathrm{T}_{\text {ign }}$ occurs, as shown in figure 6. These abrupt combustions may be due to cracking or spalling of the surface oxides which expose unoxidized or partially oxidized material. If the surface oxides are impeding the transfer of oxygen to the oxidizing surface the resulting rapid increase in oxidation rate may produce sufficient heat, in a region of restricted heat loss, to melt a small volume of the alloy. This may result in immediate combustion or in a small combustion region which rapidly expands. This type of event has also been called ignition, thus creating an unavoidable dual definition for $\mathrm{T}_{\text {ign }}$

The terms "combustion" or "combustion region" are used throughout this report. This terminology usually implies evaporation and vapor phase oxidation of the fuel material. For the N07718 alloy, vapor phase combustion does not occur. For this alloy, and most others listed in table 1, combustion is the fluid-flow-enhanced oxidation of the liquid alloy. This type of fluid oxidation generates very high temperatures, $2500 \mathrm{~K}$ and higher, and develops in milliseconds as the specimen collapse. The beginning of the development of these high temperatures is called the combustion temperature, $\mathrm{T}_{\mathrm{cmb}}$, and is shown in figure 6.

\section{$\underline{\text { Results }}$}

1. Linear Temperature Scan Tests: The initial experiments in the evaluation of the ignition characteristics of the N07718 alloy were carried out using the LTS heating procedure. Heating rates of approximately 100 to $200 \mathrm{~K} / \mathrm{min}$ were used in order to determine whether the alloy had any tendency to develop abrupt solid phase combustion events similar to the liquid phase 


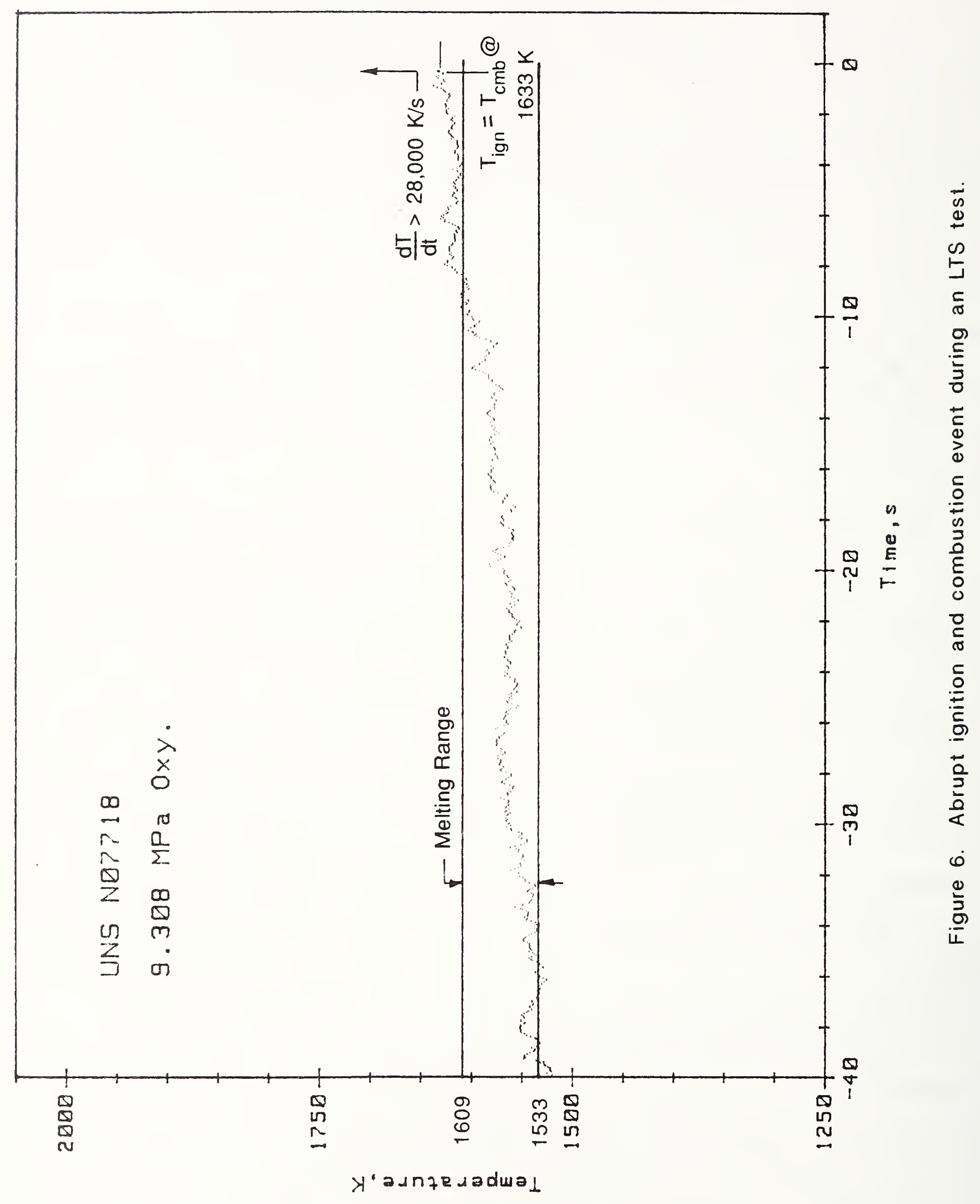


combustion event shown in figure 6. Experimental data were obtained for the oxygen pressure range of 0.7 to $13.8 \mathrm{MPa}$ (100 to $2000 \mathrm{psia}$ ). The results for a typical experiment are shown in figure 7. The waveform shows two major features. The first is the rapid increase in the rate of change in temperature at approximately $-52 \mathrm{~s}$ and the second is the abrupt ignition with immediate combustion above the liquidus temperature. Negative time in our data indicates time prior to the start of combustion or an arbitrary time afterward. Not as obvious, due to the compression of the data, are endothermic (constant temperature) features in the waveform, examples of which are shown in figure 8. These features generally had a short duration due to the temperature scan rate used in the experiments.

The rapid increase in the rate of change in temperature in figure 7 , starting at approximately $-52 \mathrm{~s}$, appeared to be due to an increasingly rapid rate of oxidation of the alloy which caused the specimen to autoheat faster than control of the heating ramp could offset. However, as laser power was continuously reduced and the oxide layer thickness increased (which reduces heat transfer to the oxidation zone from the laser), the heating ramp was eventually reestablished (although at a different rate). In many tests, the autoheating appeared to develop in conjunction with endothermic features in the waveform. Endothermic events also appeared at other temperatures and often appeared to increase the rate of change in specimen temperature. Also, the endothermic features were often associated with the development of temperature spikes, exothermic events, ignition, and the beginning of combustion.

The oxides produced during oxidation were significantly less dense than the alloy. The density difference created considerable mechanical stress 


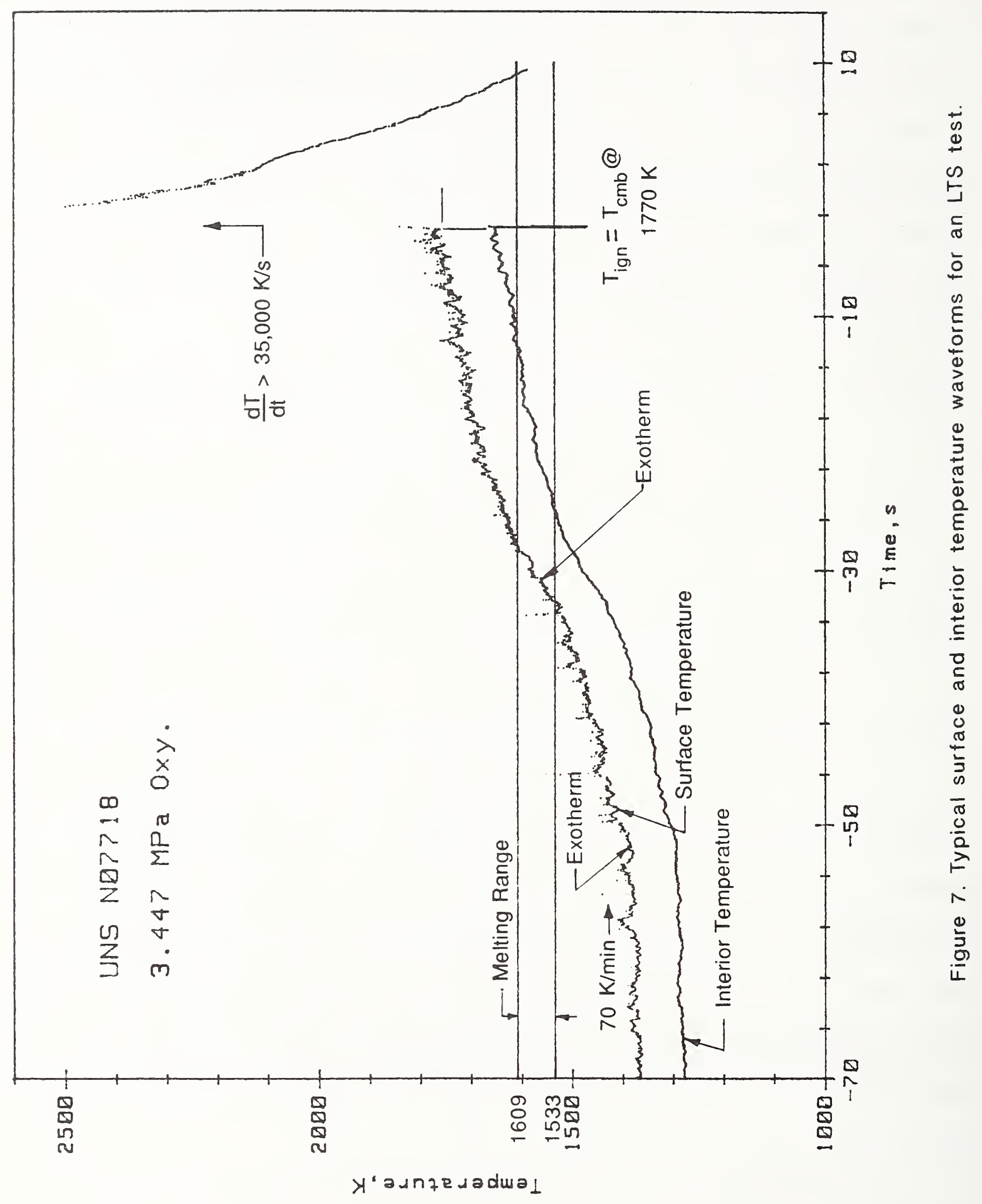


which was released by cracking and spalling of the oxide surface. This cracking and spalling produced small particles and/or structures that could be heated to very high temperatures before they would vaporize or melt, adhere to the substrate oxide layer and cool to the baseline temperature. The net effect of the particle and/or structure heating and cooling was to produce a rapid increase, then decrease, in apparent surface temperature, which we have called a temperature spike, as shown in figure 8 . These spikes did not appear to have any permanent effect upon the baseline temperature or the rate of change in the baseline temperature. Therefore, the spikes are not considered to have had an effect upon the oxidation rate of the alloy. The series of spikes noted in figure 8 (others are also present) were probably produced by the breakup of a fairly large piece of oxide.

Another surface temperature waveform feature had the appearance of a fast exothermic event with limited energy as shown in figure 8 . (In this report we differentiate between exothermic features (events), which occur in milliseconds to several seconds and have an apparently small energy release, and the much slower exothermic oxidation process or the exothermic combustion process, which has a massive energy content.) These events appeared to initiate permanent changes in the baseline temperature or increases in the rate of change in surface temperature. These events were usually abrupt, occurring within milliseconds to several hundred milliseconds and were often preceded by an endothermic feature. Exothermic events are considered to be caused by small rapid changes in oxidation rate of the alloy.

At an oxygen pressure of $0.7 \mathrm{MPa}$ (100 psia), the development of combustion from ignition occurred only after significant melting of the specimen. However, at an oxygen pressure of $1.7 \mathrm{MPa}$ (250 psia) or greater, 


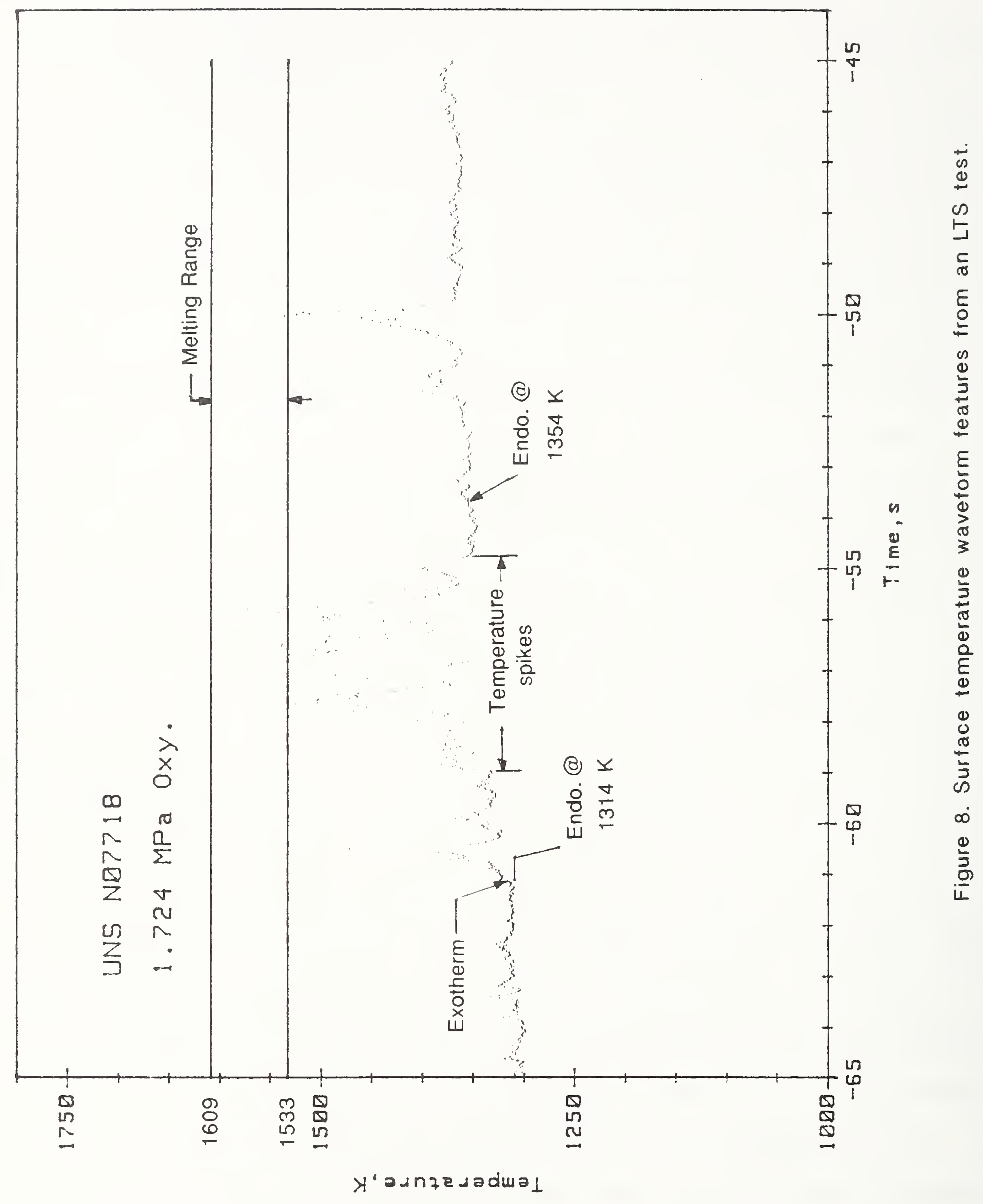


combustion developed after ignition within milliseconds to several seconds and with minimal melting of the specimen, the second major feature of figure 7 .

The ignition data for the LTS test are listed in table 2 and plotted in figure 9. Figure 10 shows the combustion temperatures, that is, the temperatures at which the specimen began to rapidly melt and fluid flow enhanced oxidation began; these data are also listed in table 2. As seen in figure 9, the surface temperatures at ignition lie above the liquidus temperature of the alloy for oxygen pressures up to $6.9 \mathrm{MPa}$ (1000 fsia). At oxygen pressures greater than $6.9 \mathrm{MPa}$ the ignition temperatures began to fall into the melting range, and at oxygen pressures greater than $9.3 \mathrm{MPa}$ (1350 psia) they fall predominantly below the solidus temperature.

It was clear that exothermic events occurred while the alloy was in the solid state and ignition began to develop from these events at oxygen pressures greater than $9.3 \mathrm{MPa}$ (1350 psia). These events released sufficient heat to increase the baseline temperature or the rate of change in baseline temperature following their occurrence. We concluded that the exotherms were due to a rapid change in oxidation rate of the alloy. Since endotherms, probably melting transitions, are often involved, we assumed that the oxidation rate of the alloy was affected by the source of these events. However, the source has not yet been established. As the alloy specimen began to melt, abrupt ignition to combustion transitions occurred. The transitions were thought to occur as the upper surface cracked or ruptured due to the expansion of the liquefying alloy. It also appeared that the rate of oxidation of the alloy increased significantly as the surface temperature entered the 1300-1450 $\mathrm{K}$ temperature range. The rate of the temperature 
Table 2. LTS ignition and combustion temperatures

\begin{tabular}{|c|c|c|c|c|c|}
\hline ! & \multirow{2}{*}{$\begin{array}{c}\text { Pressure } \\
\mathrm{MPa}\end{array}$} & \multicolumn{2}{|c|}{$\mathrm{T}_{\text {ign, }} \mathrm{K}$} & \multicolumn{2}{|c|}{$\mathrm{T}_{\mathrm{cmb}}, \mathrm{K}$} \\
\hline$i$ & & ISurface & Interior & Surface & Interior \\
\hline 1 & 0.689 & 1718 & 1854 & 1752 & 1907 \\
\hline 1 & 0.689 & 11642 & 1819 & 1644 & 1850 \\
\hline$\perp$ & 1.724 & 11670 & 1811 & 1692 & 1876 \\
\hline 1 & 1.724 & 11696 & 1851 & 11733 & 1970 \\
\hline$L$ & 1.724 & 11734 & 1813 & 11780 & 1897 \\
\hline$\perp$ & 1.724 & 1685 & 1815 & 1685 & 1815 \\
\hline$\perp$ & 1.724 & 1606 & 1750 & 1647 & 1903 \\
\hline$\perp$ & 1.834 & 1667 & 1787 & 1676 & 1802 \\
\hline$\perp$ & 3.447 & 1620 & 1729 & 1620 & 1729 \\
\hline$\perp$ & 3.447 & 1652 & 1770 & 11652 & 1770 \\
\hline$L$ & 3.447 & 1637 & 1722 & 1678 & 1785 \\
\hline$\perp$ & 3.447 & 11575 & 1731 & 11575 & 1731 \\
\hline$\perp$ & 3.447 & 11603 & 1793 & 1603 & 1793 \\
\hline 1 & 3.447 & 11542 & 1697 & 1542 & 1697 \\
\hline 1 & 5.171 & 1594 & 1685 & 1594 & 1685 \\
\hline 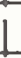 & 5.171 & $\begin{array}{l}1539 \\
\end{array}$ & 1667 & 11539 & 1667 \\
\hline$\perp$ & 5.171 & 11541 & 1730 & 1541 & 1730 \\
\hline$\perp$ & 6.895 & \begin{tabular}{|l}
1494 \\
\end{tabular} & 1667 & 11494 & 1667 \\
\hline 1 & 6.895 & 1599 & 1726 & 1598 & 1749 \\
\hline$\perp$ & 6.895 & 1633 & 1727 & 1633 & 1727 \\
\hline 1 & 6.895 & 1549 & 1656 & 11554 & 1692 \\
\hline 1 & 9.080 & 11524 & 1630 & 1524 & 1630 \\
\hline 1 & 9.308 & 1539 & 1633 & 11539 & 1633 \\
\hline 1 & 9.356 & 1526 & 1696 & 1526 & 1969 \\
\hline 1 & 9.370 & 1487 & 1580 & 1509 & 1603 \\
\hline 1 & 10.342 & 11431 & 1580 & 1431 & 1580 \\
\hline 1 & 11.011 & 11412 & 1507 & 11500 & 1617 \\
\hline$\perp$ & 11.052 & 1340 & 1460 & 1430 & 1591 \\
\hline$\perp$ & 11.052 & 11213 & 1371 & $\begin{array}{l}1357 \\
\end{array}$ & 1622 \\
\hline 1 & 11.625 & 11291 & 1433 & 11397 & 1623 \\
\hline 1 & 12.507 & 11380 & 1548 & 11383 & 1572 \\
\hline$\perp$ & 12.735 & 1206 & 1336 & 1322 & 1465 \\
\hline 1 & 12.900 & 11339 & 1482 & 1387 & 1568 \\
\hline 1 & 13.004 & 11254 & 1375 & 1314 & 1544 \\
\hline 1 & 13700 & 11321 & 1445 & $\begin{array}{l}1321 \\
\end{array}$ & 1445 \\
\hline 1 & 14.162 & 11412 & 1569 & 11461 & 1642 \\
\hline 1 & 14.465 & 11492 & 1696 & 1492 & 1696 \\
\hline 1 & 14.610 & 11368 & 1498 & 1403 & 1555 \\
\hline & 14.644 & 11281 & 1420 & 1260 & 1564 \\
\hline
\end{tabular}




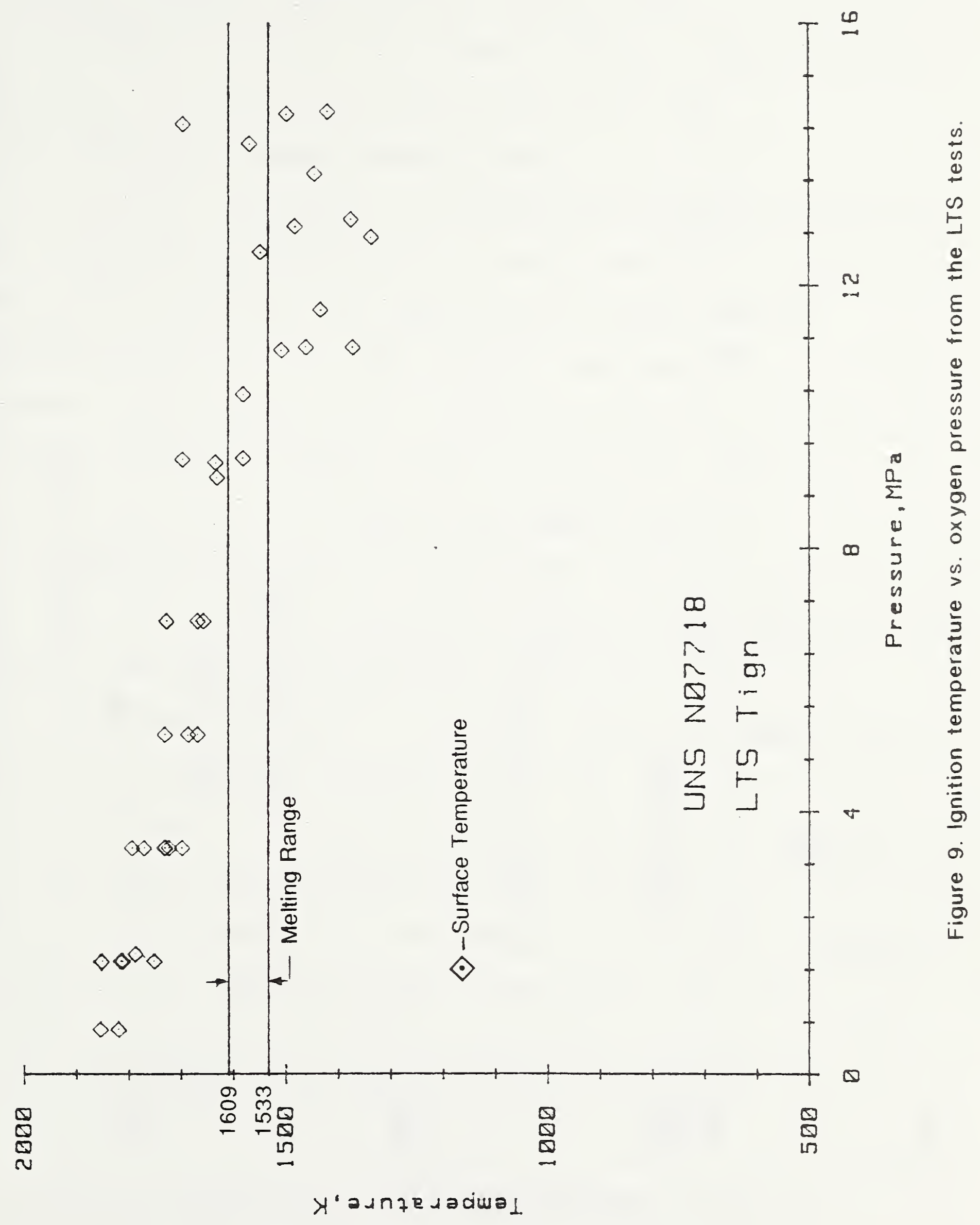




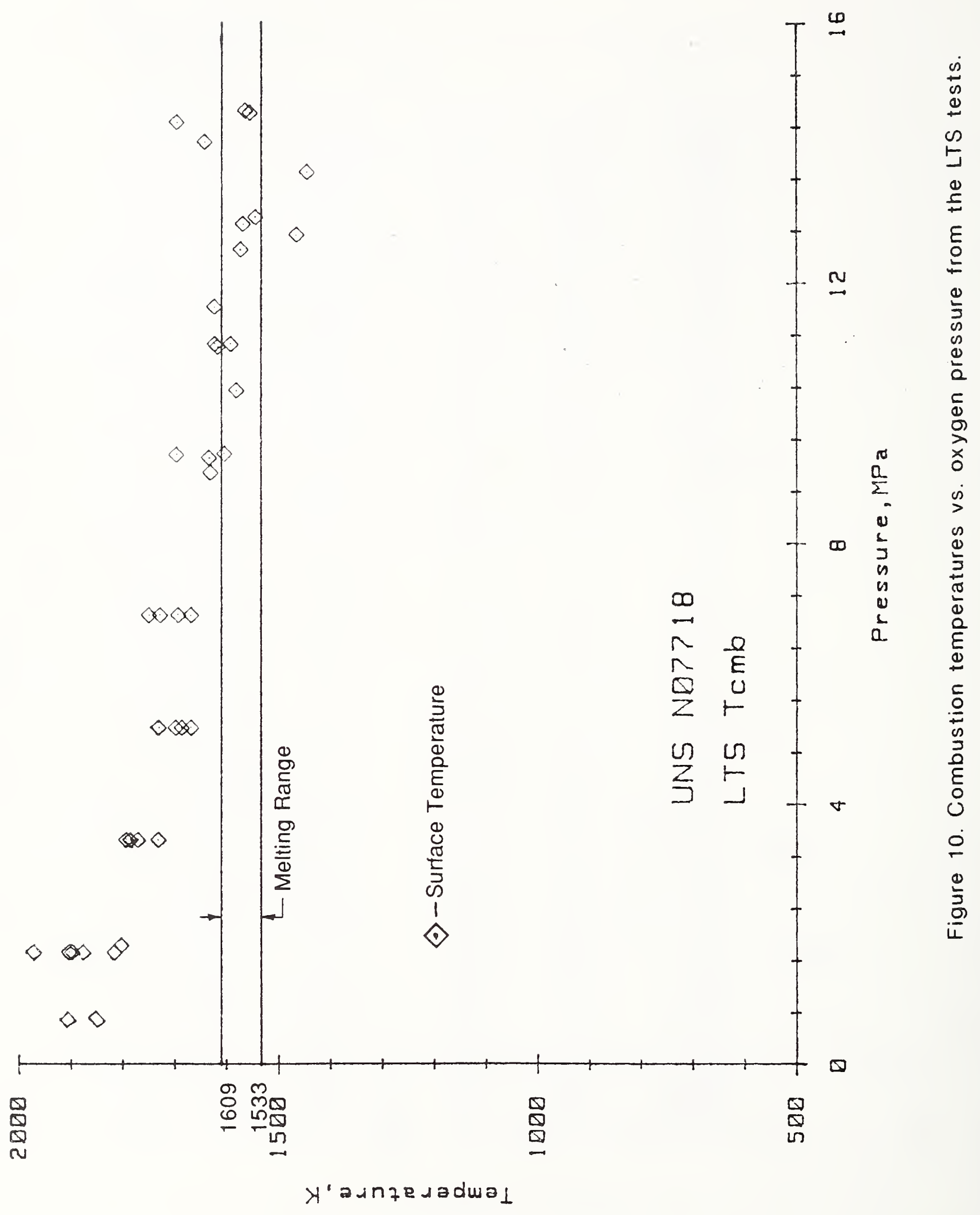


increase in this range suggested that the alloy could autoheat to destruction. Because of this tendency, a series of experiments were run to investigate this phenomenon. Also, standard differential thermal analysis (DTA) studies were made on oxidizing samples of the alloy.

\section{Differential Thermal Analysis Studies:}

The appearance of features in the temperature-time waveform from the LTs tests, interpreted as endothermic and exothermic events, led to efforts to verify this interpretation. The approach was to utilize standard Differential Thermal Analysis (DTA) techniques and equipment and search for endothermic and exothermic events. Testing was carried out in flowing oxygen or helium at atmospheric pressure using $15-50 \mathrm{mg}$ specimens heated to temperatures greater than the lower melting range of the alloy.

The tests in helium provided a baseline for comparison to the oxidation tests. These tests produced featureless thermographs except for the melting transition. However, the tests in oxygen demonstrated that the oxides produced during heating exhibited considerable thermal activity, as shown in figure 11. This figure is a composite of two runs. It is occasionally necessary to combine several runs to obtain an overall view of the events which occur over an extended temperature range. Endothermic and exothermic transitions were present, but the temperatures of the individual transitions could not be firmly established because of their number and weakness. The weakness of the transitions was due to the small mass of responding material--a thin layer on the surface of a 15 to $50 \mathrm{mg}$ disk of alloy.

The presence of liquid and probably gaseous oxides was evident from the discoloration, and eventual destruction, of the aluminum oxide sample holders. Several investigators have postulated or observed the presence of 


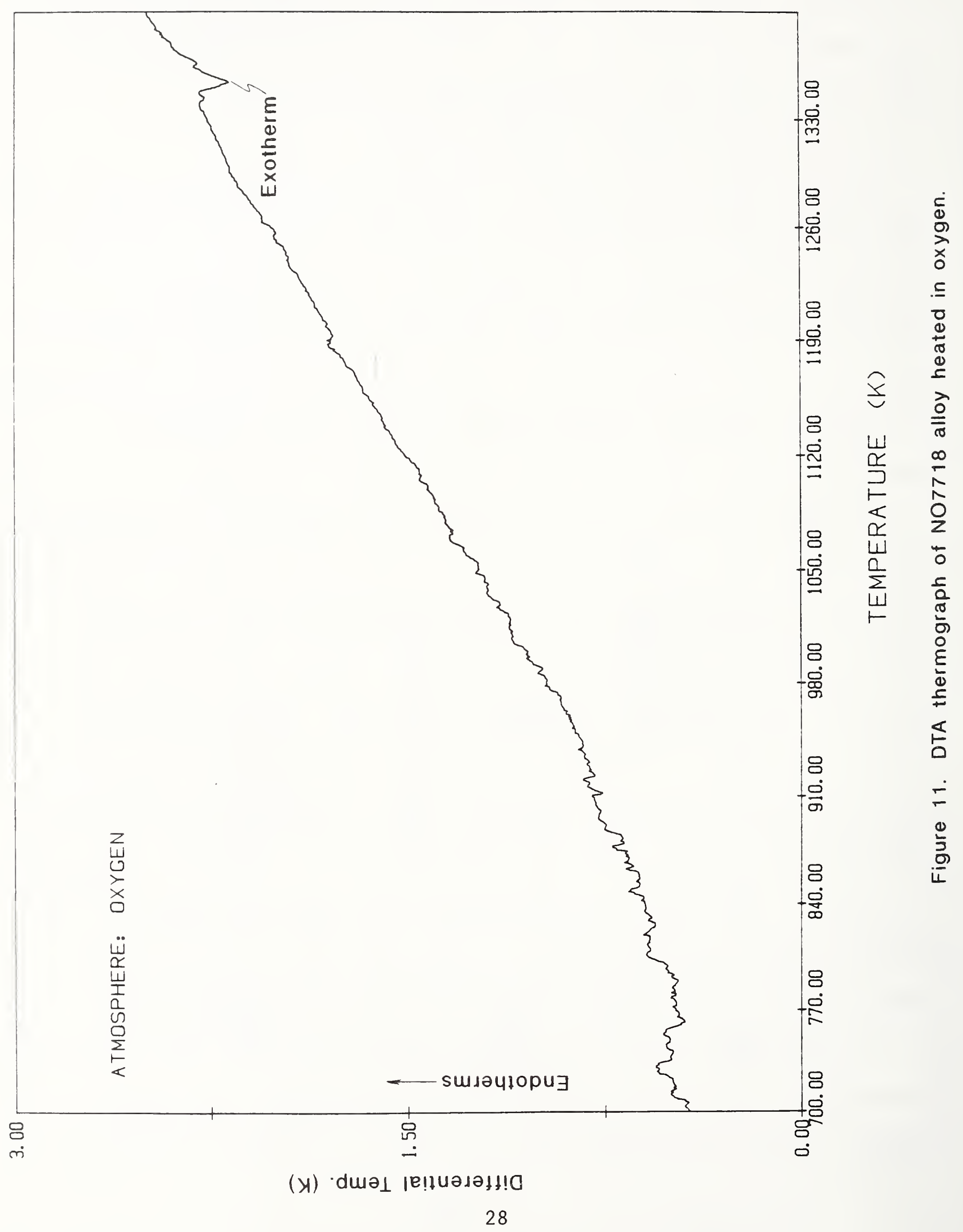


liquid oxides during the high-temperature oxidation of alloys [4,5]. These investigators have also observed increased oxidation rates when liquid oxides were present. This tended to corroborate our observations of apparently increased oxidation rates at temperatures where many endothermic transitions occurred.

These studies also corroborate the existence of low-energy exotherms and the existence of at least one high-energy exothermic event as shown in figure 11. These studies also provided an independent verification that the alloy does autoheat at temperatures below the solidus temperature of the alloy.

\section{Incremental Temperature Scan Tests:}

The experiments to investigate the tendency of the alloy to autoheat to destruction were performed using the ITS heating procedure. This procedure applied a constant laser power to the specimen which was increased at intervals, after surface temperature equilibrium was established, until the specimen began to autoheat. The external heating rate was then held constant until autoheating ceased or combustion occurred. Figure 12 shows the surface and interior temperature-time waveforms for a typical experiment. These waveforms show more clearly the endothermic and exothermic features that were observed in the waveforms from the LTS experiments. Only a few features are noted. The endothermic and exothermic features and their effects on the baseline temperature and rate of change in the baseline temperature are more clearly shown in figures 13 and 14; only the more prominent features are noted. These figures are expansions of waveform sections, chosen for their clarity, from several experiments. The converging slopes of the surface and interior temperature waveforms of these figures also show that the surface temperature measurement was adversely affected by the oxide surface, probably 


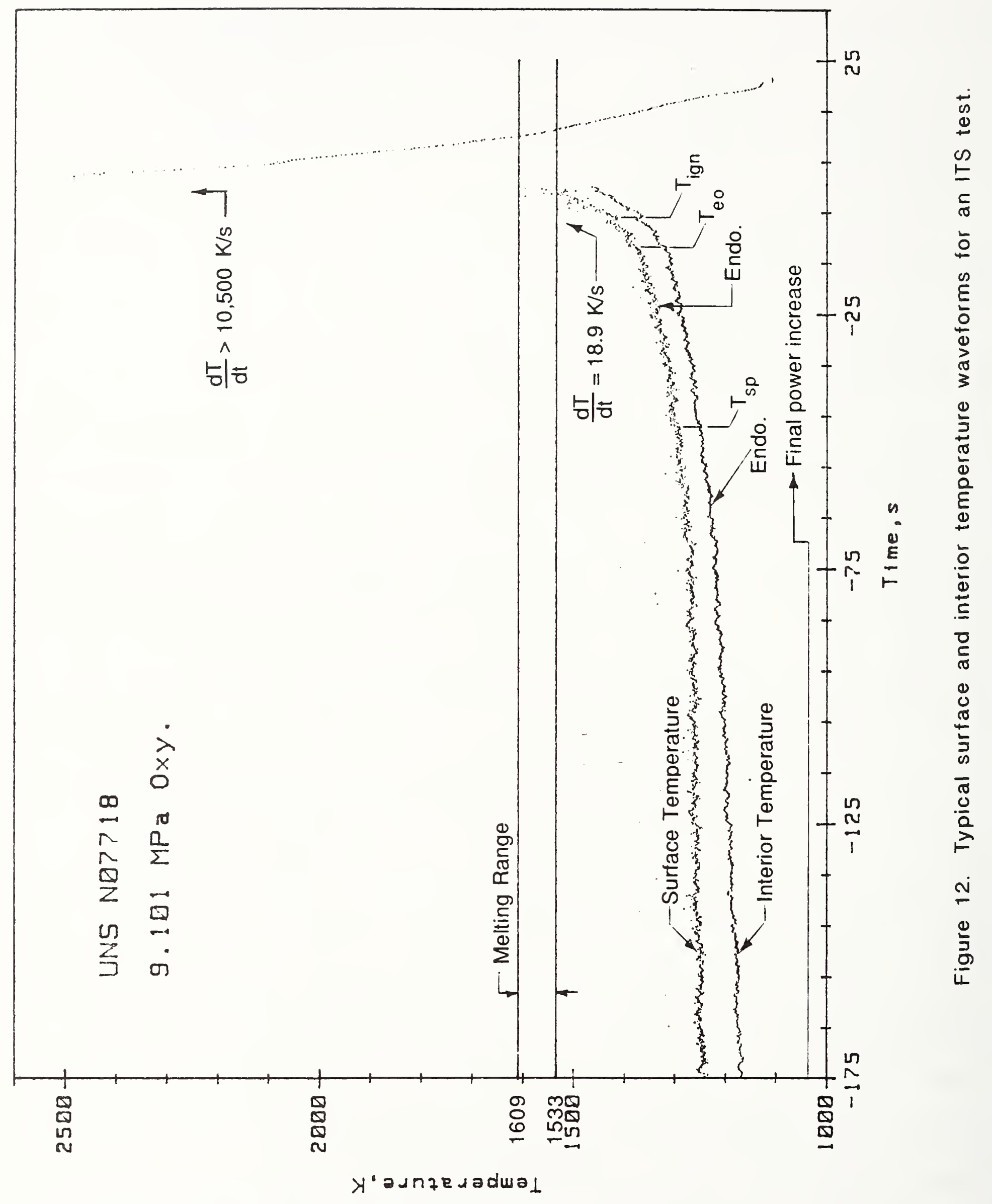




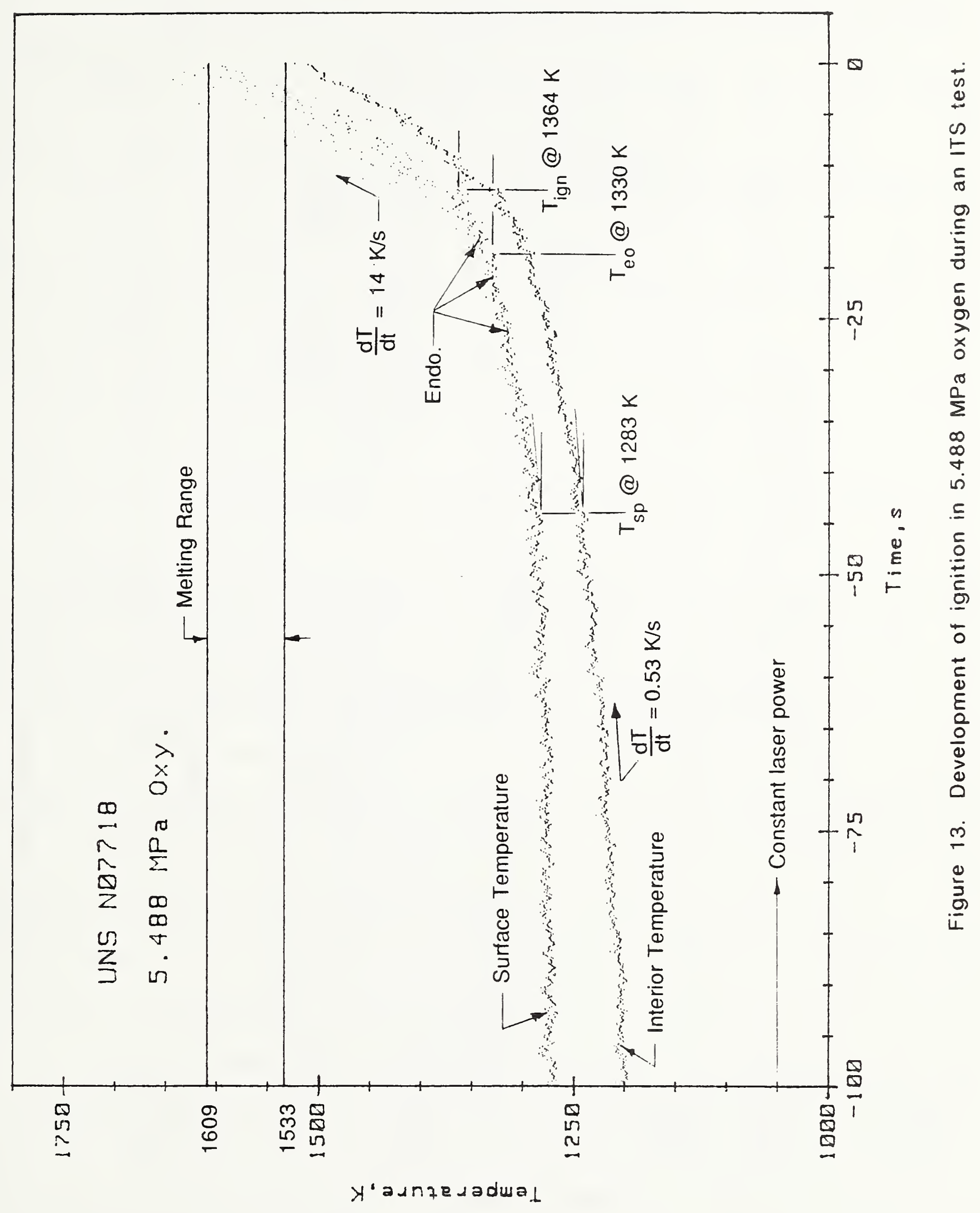




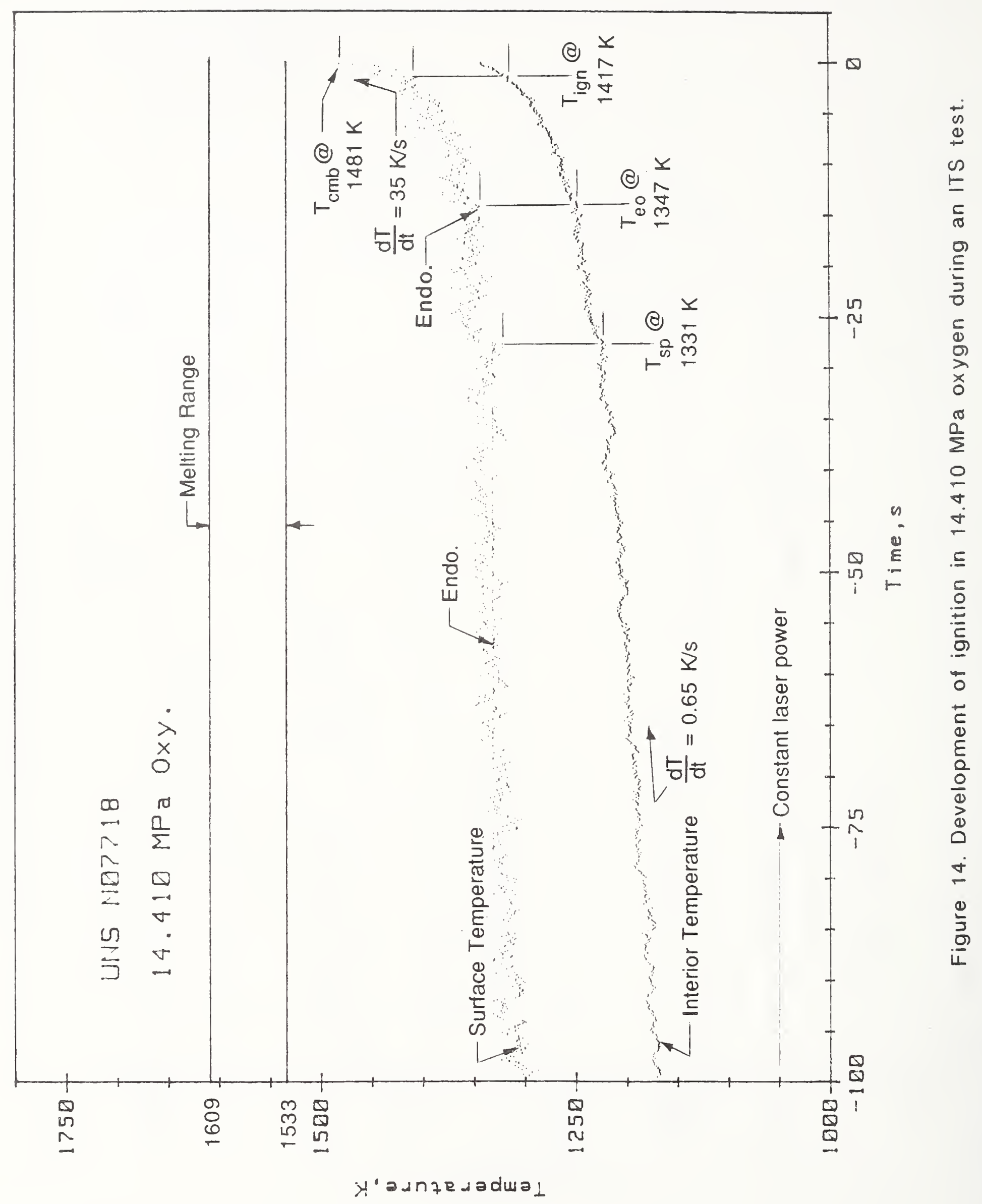


due to the surface emissivity. However, the error introduced was minimal at temperatures equal to or greater than $\mathrm{T}_{\mathrm{sp}}$. Because the error was minimal (approximately 1 to 1.5 percent at $\mathrm{T}_{\mathrm{sp}}$ and less at higher temperatures) the surface temperature data for the ignition parameters was not adjusted.

Figure 13 shows a rate of increase in temperature of approximately 0.5 $\mathrm{K} / \mathrm{s}$ (interior temperature waveform) after the last power increment. This initial autoheating was due primarily to the increasing absorptivity of the surface to the laser radiation [3]. An oxidation component to the heating rate was also present but very small. However, as the specimen temperature increased the oxidation component to the heating rate steadily increased at a nonlinear rate. The oxidation component ultimately became the principal heat source driving the increase in specimen temperature at the spontaneous ignition temperature. The slight curvature in the interior temperature-time waveform between $-100 \mathrm{~s}$ and $\mathrm{T}_{\mathrm{sp}}$ was thought to be due to the increasing oxidation rate component to the heating rate. $\mathrm{T}_{\mathrm{sp}}$ was chosen as the beginning of the interior temperature-time waveform section where it appeared clear that oxidation heat input to the system was the dominant heat source in increasing the specimen temperature. This was the beginning of the clearly nonlinear section of the interior temperature-time waveform.

Figure 14 shows the effect of increased oxygen pressure on the rate of increase in temperature. As can be seen the rate of temperature increase prior to $\mathrm{T}_{\mathrm{sp}}$ was approximately the same as in the much lower oxygen pressure experiment shown in figure 13. This was additional evidence that the heating rate at temperatures below $\mathrm{T}_{\mathrm{sp}}$ was due primarily to increasing absorptivity of the developing oxide layer to the laser radiation. Also, the rate of increase in temperature after $\mathrm{T}_{\text {ign }}$ was significantly greater than the values 
shown in figures 12 and 13. This figure also shows that combustion may begin while the alloy is in the solid state, or at least develop faster than the data acquisition rate of 0.1 second per data point used in this experiment.

After spontaneous ignition was achieved, the rate of change in specimen temperature began to slowly increase. This increase was usually followed by several exothermic features (step increases in the baseline temperature) which were associated with endothermic features or features which may be weak endotherms. The result of these apparent exothermic events was an abrupt change in curvature of the temperature-time waveform. An attempt was made to quantify the onset of this abrupt change in curvature by relating it to the temperature of features in the temperature-time waveform. Since it is our premise that the exothermic features are associated with rapid changes in the oxidation rate of the alloy, this temperature was called the enhanced oxidation temperature, $\mathrm{T}_{\mathrm{eo}}$. After $\mathrm{T}_{\mathrm{e}}$ occurred the rate of change in temperature continued to increase until a maximum rate of change was reached. The temperature at which this occurred was considered to be the temperature at which the maximum deviation between the $\dot{Q}(i n)$ and $\dot{Q}($ loss) curves occurred for the solid phase oxidation. Thus, this temperature was taken as $\mathrm{T}_{\text {ign }}$. The values of the ignition parameters $-\mathrm{T}_{\mathbf{s p}}, \mathrm{T}_{\text {eo }}$ and $\mathrm{T}_{\mathrm{ign}}{ }^{-}$are listed in table 3 and plotted as a function of oxygen pressure in figures 15, 16, and 17. The data were fitted to linear least-squares curves so that trends in the data, with respect to oxygen pressure, could be established. The slopes of the trends are noted on the plots and the linear fit parameters are given in table 4 .

The values of the ignition parameters decreased with increasing oxygen pressure in a linear trend over the oxygen pressure range of the data. 
Table 3. ITS ignition parameter temperatures

\begin{tabular}{|c|c|c|c|c|c|c|}
\hline \multirow{2}{*}{$\begin{array}{c}\text { Pressure } \\
\mathrm{MPa}\end{array}$} & \multicolumn{2}{|c|}{$\mathrm{T}_{\text {sp }}, \mathrm{K}$} & \multicolumn{2}{|c|}{$\mathrm{T}_{\text {eo }}, \mathrm{K}$} & \multicolumn{2}{|c|}{$\mathrm{T}_{\text {ig }}, \mathrm{K}$} \\
\hline & Interior & Surface & Interior & Surface & Interior & Surface \\
\hline 1.834 & $\perp 1255$ & 1309 & $1 \quad 1299$ & 1359 & 1373 & 1450 \\
\hline 1.834 & 1294 & 1337 & 1345 & 1384 & 1391 & 1437 \\
\hline 1.868 & 1262 & 1312 & 1317 & 1360 & 1368 & 1423 \\
\hline 3.627 & $\perp$ & 1324 & $\perp$ & 1363 & $\perp$ & 1441 \\
\hline 3.640 & 1261 & 1316 & 1284 & 1341 & 1347 & 1428 \\
\hline 3.654 & $i$ & 1305 & 1 & 1362 & 1 & 1435 \\
\hline 5.378 & 1265 & 1305 & 1294 & 1335 & 1353 & 1395 \\
\hline 5.440 & 1245 & 1321 & 1263 & 1331 & 1321 & 1385 \\
\hline 5.488 & 1236 & 1283 & 1288 & 1330 & 1324 & 1364 \\
\hline 5.495 & $i$ & 1299 & $\perp$ & 1331 & $\perp$ & 1362 \\
\hline 7.226 & 1205 & 1298 & 1262 & 1330 & 1294 & 1360 \\
\hline 7.253 & 1240 & 1294 & 1291 & 1330 & 1319 & 1354 \\
\hline 7.260 & 1238 & 1291 & 1303 & 1337 & 1357 & 1399 \\
\hline 18.991 & 1233 & 1308 & 1295 & 1361 & 1327 & 1394 \\
\hline 19.060 & $1 \quad 1255$ & 1315 & 1272 & 1330 & 1333 & 1392 \\
\hline 9.101 & 1248 & 1291 & 1291 & 1340 & 1367 & 1414 \\
\hline 110.832 & $\perp \quad 1204$ & 1299 & 1266 & 1330 & 1299 & 1372 \\
\hline 12.169 & 1241 & 1326 & 1269 & 1330 & 1307 & 1353 \\
\hline 12.493 & 1208 & 1318 & 1248 & 1353 & 1276 & 1372 \\
\hline 12.686 & 1266 & 1313 & 1279 & 1324 & 1325 & 1374 \\
\hline 14.348 & $1 \quad 1134$ & 1251 & 1185 & 1311 & 1256 & 1387 \\
\hline 14.410 & $1 \quad 1222$ & 1331 & 1248 & 1347 & 1294 & 1387 \\
\hline
\end{tabular}




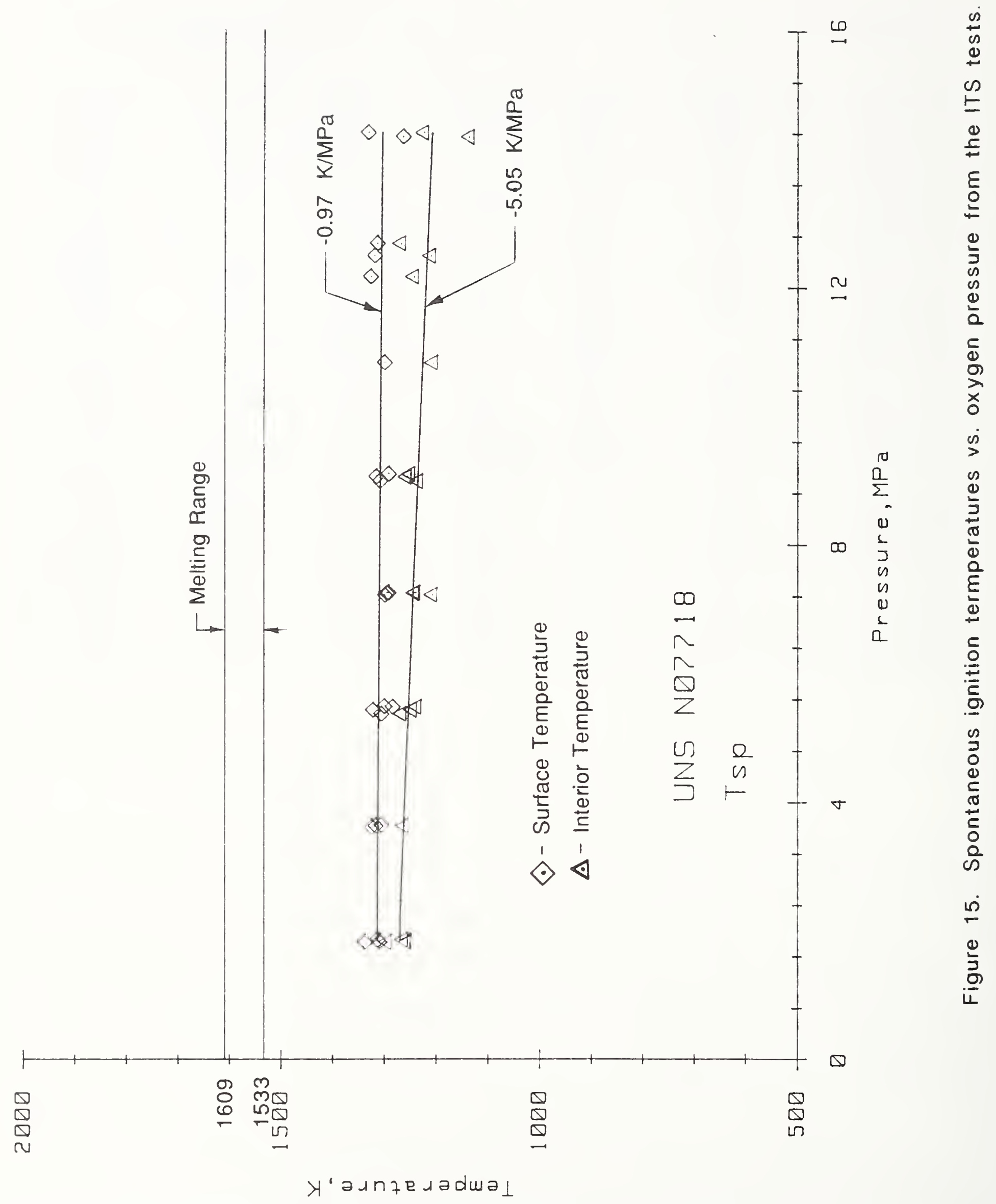




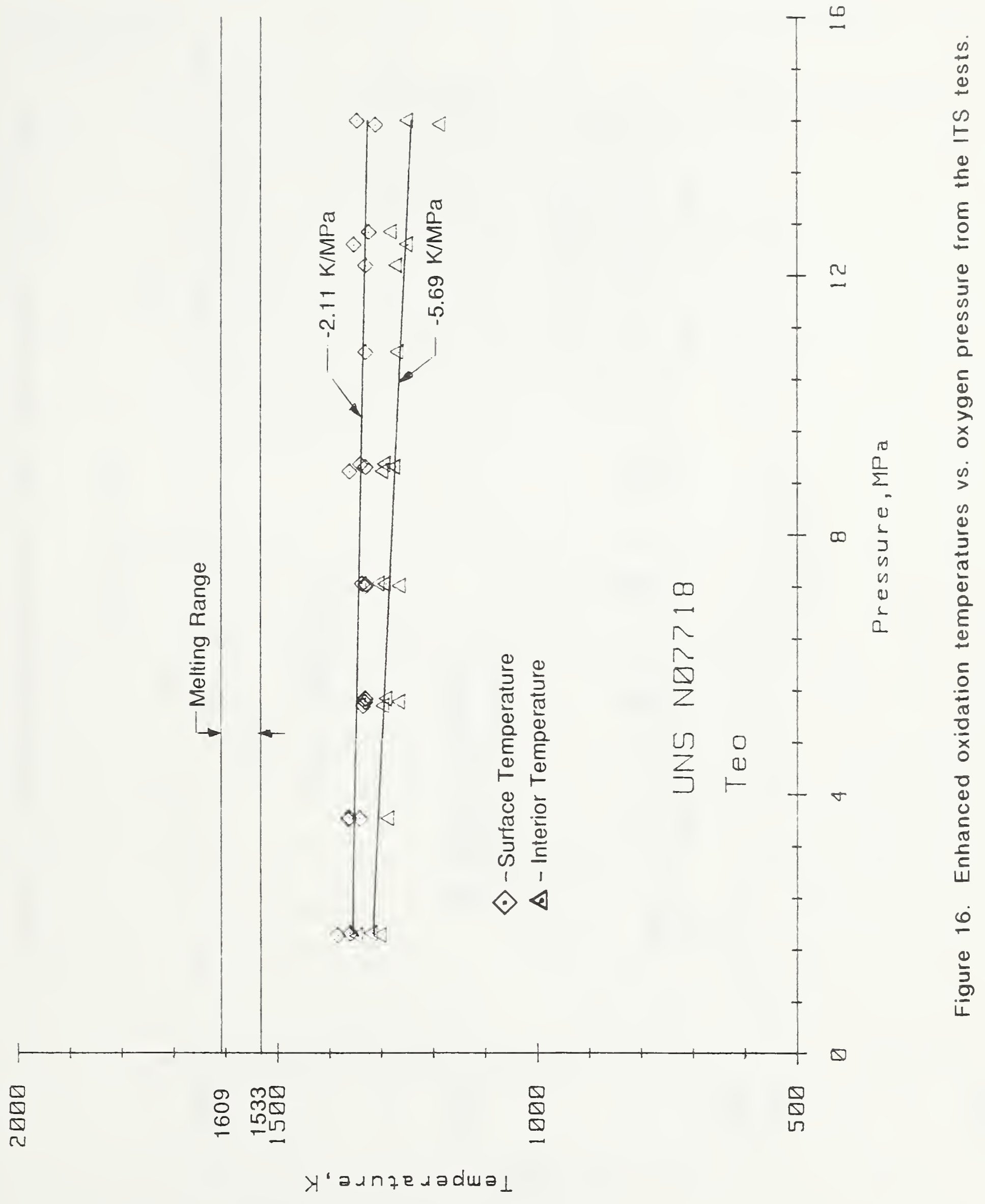




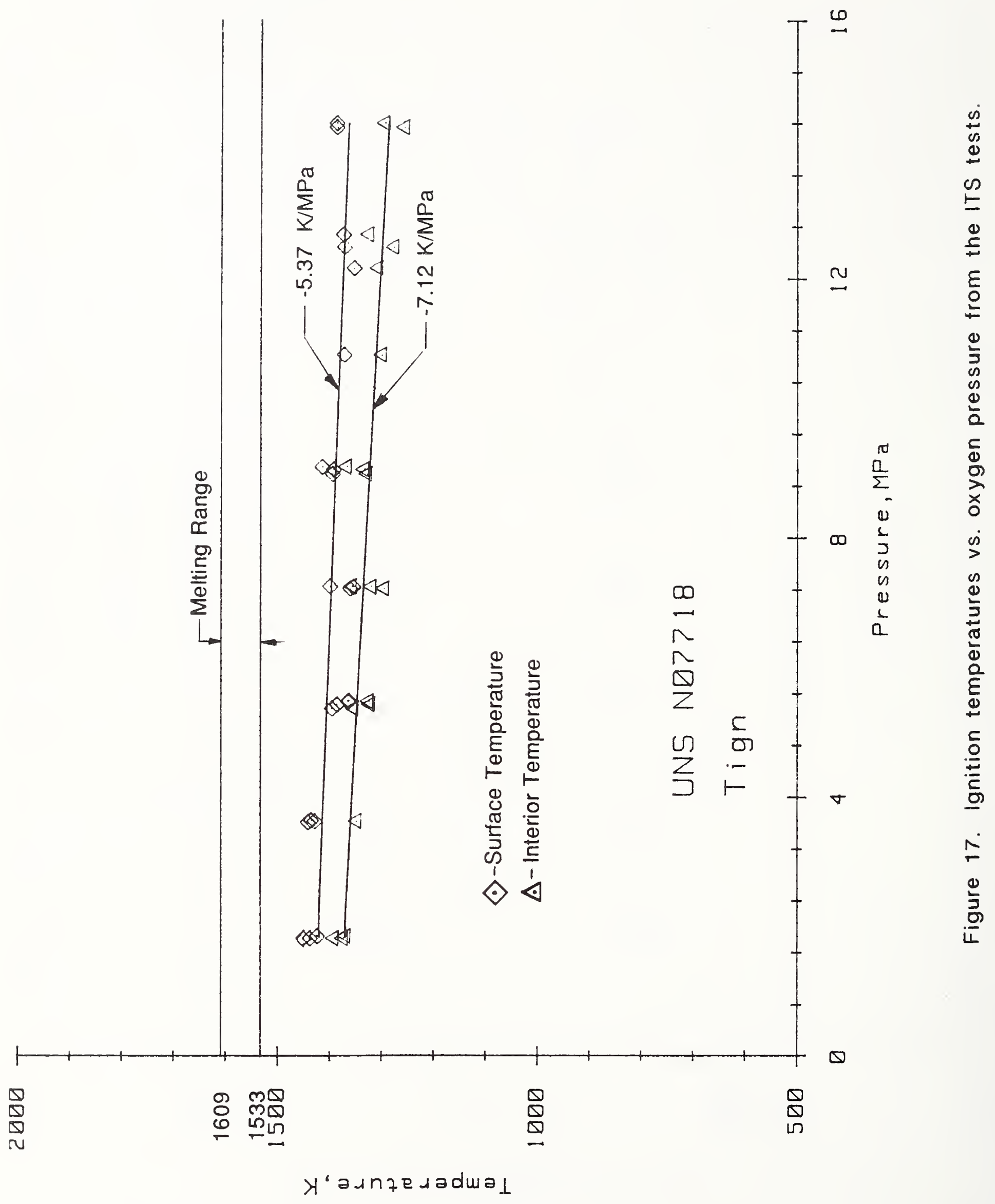


Table 4. Linear least-squares curve fit coefficients for the ITS ignition parameter data

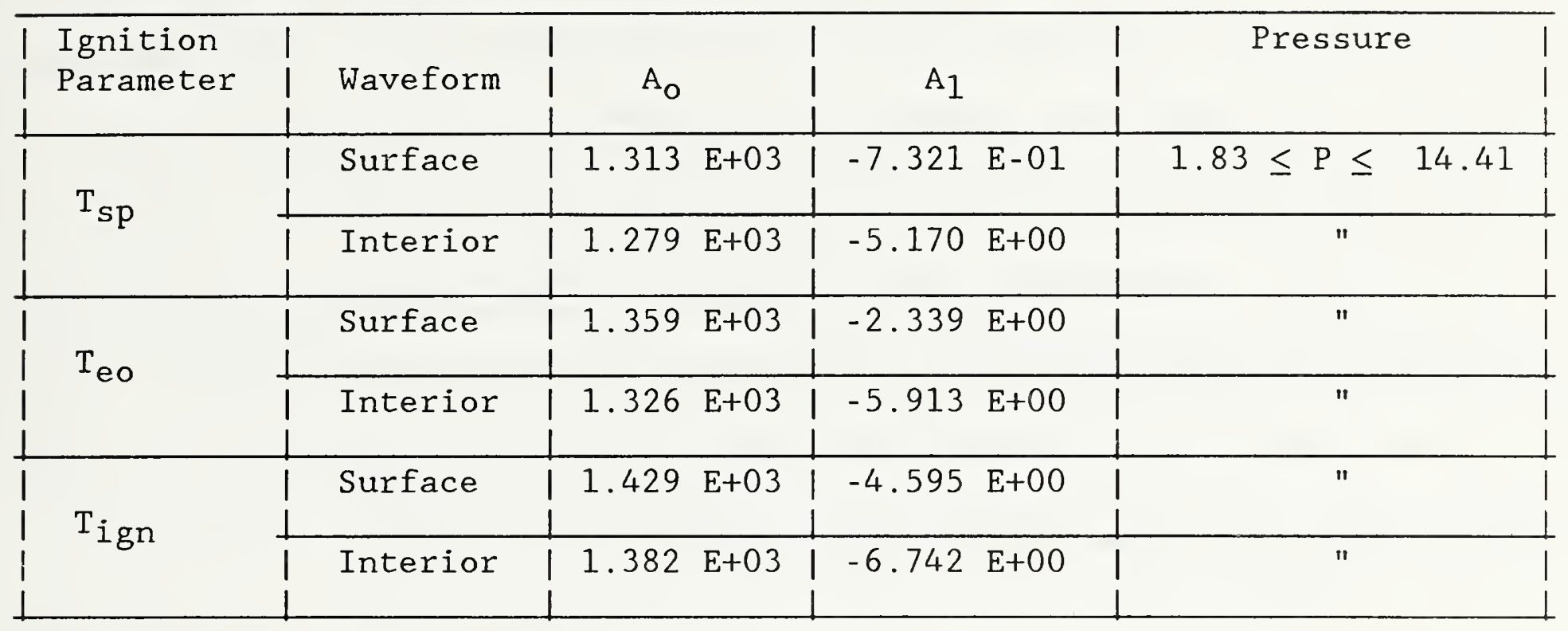


However, this decrease was not large. Also, the surface temperature diverged from the interior temperature for each ignition parameter. This was probably due to an increasingly thicker oxide layer which developed as oxygen pressure increased and impeded heat transfer to the interior.

\section{Data Accuracy:}

The surface temperature values of $\mathrm{T}_{\mathrm{Sp}}, \mathrm{T}_{\text {eo }}, \mathrm{T}_{\mathbf{i g n}}$, and $\mathrm{T}_{\mathrm{cmb}}$ contained in this report were determined with a commercial two-color ratio pyrometer with an inherent accuracy of 1 percent when measuring black or gray body temperatures. This was verified by calibration using a NIST standard lamp.

The assumption made in two-color ratio pyrometry is that the change in emissivity over the measurement wavelength band is negligibly small.

However, oxidizing surfaces are notorious for the variation in the value of emissivity with wavelength. To determine whether or not a pyrometer measurement problem existed, the difference between the surface temperature and interior (thermocouple) temperature was calculated. If this difference was constant or changed negligibly, then the pyrometer measurement was taken to be within its error limit of 1 percent. For N07718 a clear surface temperature measurement error existed for the ITS data but not for the LTS data. This error decreased as the surface temperature approached $\mathrm{T}_{\mathrm{Sp}}$ and was minimal or disappeared at temperatures greater than $\mathrm{T}_{\mathrm{sp}}$. It was estimated that the surface temperature values of $\mathrm{T}_{\mathrm{Sp}}$ were high with a maximum bias of 1 to 1.5 percent. The values of $\mathrm{T}_{\text {eo }}$ and $\mathrm{T}_{\text {ign }}$ do not appear to contain any significant bias and are assumed accurate to within the 1 percent accuracy of the instrument.

An exact error value cannot be placed on each numeric value of the ignition parameters. However, we consider that the data presented accurately 
represent the temperature of the central region of the specimen where the oxidation events occurred to within the limits discussed above.

\section{Conclusions}

The LTS data indicated that ignition could occur at temperatures below the solidus temperature for oxygen pressures greater than $11 \mathrm{MPa}$ (1600 psia). Combustion occurred predominantly within or above the melting range.

However, several combustion events began at temperatures below the solidus temperature at oxygen pressures exceeding $12 \mathrm{MPa}$ (1750.psia). Therefore, this alloy has a "sudden failure" characteristic under this test mode if the oxygen pressure is sufficiently high.

The ITS data established that (under the appropriate experimental conditions) the oxidation rate of the alloy was sufficient for the alloy to autoheat to destruction, from temperatures below the solidus temperature. This was independently verified by the DTA data. These data also indicated that certain oxides produced during heating undergo phase changes, probably melting, at various temperatures. As some phase changes occur, apparent increases in oxidation rate of the alloy also occur.

The time required for the development of combustion after ignition decreased as oxygen pressure increased. Some combustion events developed below the solidus temperature at oxygen pressures of $10.3 \mathrm{MPa}$ (1500 psi) and greater. The transition times from ignition to combustion at these pressures were so short that the alloy may be considered to have a "sudden failure" characteristic under this test mode. The temperatures at which the ignition parameters occurred decreased with increasing oxygen pressure in a linear manner. This indicates that these parameters are a function of the oxidation 
rate of the alloy and that the oxidation rate increases more rapidly with increasing oxygen pressure than the cooling rate for the ITS test procedure.

\section{Future Effort}

The program, of which this study is a part, has recently been expanded to include the direct determination of oxidation rates of selected alloys. To achieve this, a thermogravimetric apparatus (TGA), which will use a microgram balance housed in a pressure chamber to directly measure the oxidation rate, is being constructed. The system has been designed to operate to pressures of $34.5 \mathrm{MPa}$ (5000 psia) and to temperatures greater than $1700 \mathrm{~K}$. This equipment will be used to generate oxidation rate data as a function of time, temperature, and oxygen pressure. From these data, the $\dot{Q}($ chem) curve can be determined. Once the $\dot{Q}($ chem) curve is known, computer modeling of system designs and potential abnormal operating conditions can be accomplished and the most appropriate materials chosen.

\section{Acknowledgment}

The authors express their appreciation to John G. Austin, Jr., technical representative, George C. Marshall Space Flight Center, for his many valuable contributions to this study and the overall program and to the George C. Marshall Space Flight Center for funding.

\section{$\underline{\text { References }}$}

[1] Mellor, A.M., "Heterogeneous Ignition of Metals: Model and Experiment." Ph.D. thesis, Princeton University, Princeton, NJ, 1968.

[2] Bransford, James W., Billiard, Phillip A., Hurley, James A., and Vazquez, Isaura, The Development of Combustion from Quasi-Stable Temperatures for the Iron Based Alloy UNS S66286; ASTM SP 986, pages 146- 157 (1988). 
[3] Bransford, James W., et al., Ignition Characteristics of the Iron Based Alloy UNS S66289 in Pressurized Oxygen, NISTIR 88-3904, Nov. 1988.

[4] Brenner, S.S., Catastrophic Oxidation of Some Molybdenum-Containing Alloys, J. Electrochem. Soc., Vol. 102, No. 1, p. 16 (1954).

[5] Rathenau, G.W. and Meijering, J.L., Rapid Oxidation of Metals and Alloys in the Presence of $\mathrm{MoO}_{3}$, Metallurgia, Vol. 42, p. 167 (1950). 

NBS-1 14A (REV. 2-8C)

U.S. DEPT. OF COMM.

BIBLIOGRAPHIC DATA

SHEET (See in structions)
1. PUBLICATION OR

REPORT NO.

NISTIR 89-3911
2. Performing Organ. Report No. 3. Publication Date

April 1989

4. TITLE AND SUBTITLE

Ignition Characteristics of the Nickel-Based Alloy

UNS N07718 in Pressurized Oxygen

5. AUTHOR(S) James W. Bransford, Phillip A. Billiard, James A. Hurley, Kathleen M. McDermott, and Isaura Vazquez

6. PERFORMING ORGANIZATION (If joint or other than NBS, see instructions)

National Institute of Standards and Technology

HA-THONAL-BUREAHEF STANDARES

DEPARTMENT OF COMMERCE

WASHINGTON, D.C. 20234

9. SPONSORING ORGANIZATION NAME AND COMPLETE ADDRESS (Street, City, State, ZIP)

NASA/George C. Marshal1 Space Flight Center

George C. Marshal1 Space Flight Center, AL 35812

10. SUPPLEMENTARY NOTES

Document describes a computer program; SF-185, FIPS Software Summary, is attached.

11. ABSTRACT (A 200-word or less factual summary of most significant information. If document includes a significant bibliography or literature survey, mention it here)

The development of ignition and combustion in pressurized oxygen atmospheres was studied for the nickel-based alloy UNS N07718.

Ignition of the alloy was achieved by heating the top surface of a cylindrical specimen with a continuous-wave $\mathrm{CO}_{2}$ laser. Two heating procedures were used. In the first, laser power was adjusted to maintain an approximately linear increase in surface temperature. In the second, laser power was periodically increased until autoheating (self-heating) was established. It was found that the alloy would autoheat to destruction from temperatures below the solidus

temperature.

In addition, endothermic events occurred as the alloy was heated, many at reproducible temperatures. Many endothermic events occurred prior to abrupt increases in surface temperature and appeared to accelerate the rate of increase in specimen temperature. It appeared that

the source of some endotherms may increase the oxidation rate of the alloy. Ignition parameters are defined and the temperatures at which these parameters occur are given for the oxygen pressure range of 1.72 to $13.8 \mathrm{MPa}$ (250 to $2000 \mathrm{psia})$.

12. KEY WORDS (Six to twelve entries; alphabetical order; capitalize only proper names; and separate key words ty semicolons) alloys; combustion; ignition; ignition temperature; metals; nickel alloys

\section{AVAILABILITY}

X. Unlimited

$\square$ For Official Distribution. Do Not Release to NTIS

$\square$ Order From Superintendent of Documents, U.S. Government Printing Office, Washington, D.C. 20402.
14. NO. OF

PRINTED PAGES

52

15. Price

X] Order From National Technical Information Service (NTIS), Springfield, VA. 2216I 


